\title{
Conditional Mutations in Drosophila: Concept of Genes That Control Individual Development
}

\author{
Boris F. Chadov, Eugenia V. Chadova, Nina B. Fedorova \\ Institute of Cytology and Genetics, Siberian Department of Russian Academy of Sciences, \\ Novosibirsk, Russia \\ Email: boris_chadov@mail.ru
}

How to cite this paper: Chadov, B.F., Chadova, E.V. and Fedorova, N.B. (2018) Conditional Mutations in Drosophila: Concept of Genes That Control Individual Development. Advances in Bioscience and Biotechnology, 9, 243-272.

https://doi.org/10.4236/abb.2018.96017

Received: March 9, 2018

Accepted: June 16, 2018

Published: June 19, 2018

Copyright $\odot 2018$ by authors and Scientific Research Publishing Inc. This work is licensed under the Creative Commons Attribution International License (CC BY 4.0).

http://creativecommons.org/licenses/by/4.0/ (c) (i) Open Access

\begin{abstract}
The conditional mutations in D. melanogaster are produced by gamma-irradiation, maintained in laboratory cultures, and inherited as gene mutations. However, their manifestation differs from the conventional mutations by several specific features. The most noticeable specific feature is their conditional nature, i.e., a conditional mutation manifests itself in the individuals of a certain genotype being silent in the individuals with another genotype. A particular procedure for mutation recovery determines what these genotypes will be. An overwhelming number of mutations are conditional dominant lethals. The viable mutation carriers display a drastically decreased fertility. Early zygotic lethality is inherited according to parental type (maternal or paternal). The carriers of conditional mutations give the offspring with a high rate of monstrosities. The possibility for the offspring to form monstrosities is inherited according to a parental (maternal or paternal) type. The level of fertility of conditional mutants is altered by chromosomal rearrangements. The chromosomal rearrangements themselves cause a decrease in fertility. Lethality of the progenies produced by the parents carrying rearrangements is inherited according to a parental (maternal or paternal) type. The results allow for a set of logical arguments in favor of that 1) the genome has a specialized system of genes (ontogenes) that control the course of individual development; 2) unlike a classical gene, acting according to the scheme DNA $\rightarrow$ RNA $\rightarrow$ protein, the ontogene implements the regulation according to the scheme DNA $\rightarrow$ RNA; and 3) the course of individual development is programmed by double-strand RNAs produced by ontogenes in germline cells.
\end{abstract}

\section{Keywords}

Conditional Mutation, Ontogene, Germline, Parental Effect, Drosophila 


\section{Introduction}

A living organism appears owing to 1) the processes of protein, fat, and carbohydrate chemical syntheses; 2) the regulatory system that controls and provides these synthetic processes in due time and due place; and 3) self-organization of the synthesized chemical molecules and structures. As for the synthesis itself, it is known that this process is under the terms of reference of genetic system being controlled by genes. The way from DNA sequence to the molecule of a structural protein or an enzyme protein is known in every detail. However, genetic aspects of the regulatory processes and self-organization are less clear.

It has been stated at different times and with different degrees of determination that the genes that control the synthesis cannot, exclusively on their own, provide 1) the course of morphogenesis [1] [2] [3], 2) biological similarity of the organisms within a species [4], and 3) a systems-based nature characteristic of any living organism [5] [6]. In other words, the genes postulated by classical genetics control the living organism only in part rather than completely. The proponents of epigenetics share this point of view. They regard the control of regulation and self-organization as belonging to a specialized area referred to as epigenetics rather than to genetics. The distinction of epigenetics from genetics is the independence of epigenetic events from the DNA code [7] [8]. The latest research in the field of theoretical biology also suggests that the biological synthesis and the control of biological syntheses (regulation) solve different problems in the overall process of energy materialization [9]. The above considerations suggest that the current genetics still lacks the complete list of genetic elements that provide the existence of a living organism.

In the year of 2000, the mutations referred to as conditional mutations were obtained in drosophila [10] [11]. Unlike the conventional mutations, which manifest in any individual of a given species ${ }^{1}$, manifestation of a conditional mutation depends on the genotype, manifesting in the individuals of one genotype and remaining silent in another genotype. A particular procedure for mutation recovery determines what these genotypes are [4] [12].

Characteristic of the conditional mutations is a set of unusual earlier unknown properties. As a rule, these mutations (l) are lethal, (3) are dominant, (3) transfer the genome from a stable to an unstable state, (4) display a parental effect, and (5) elevate the basal metabolism [6]. A high rate of monstrosities (morphoses) and modifications in the offspring is a hallmark for the presence of a conditional mutation in an individual [13] [14].

The defects in individual development (morphoses and modifications) emerging in the offspring of mutants have suggested that these mutations denote the earlier unknown class of genes involved in the control of development. These genes were named ontogenes [4] [15] [16] [17]. Morphoses and modifications are definitely epigenetic phenomena; however, this phenomenology originated from mutations in genes-yet not in the classical "Mendelian" genes responsible

${ }^{1}$ We mean the mutations manifesting under heterozygous and homozygous conditions. 
for syntheses of individual proteins but rather in the genes destined for driving the overall course of individual development [6] [18].

Several other important properties of conditional mutations have been noticed. These mutations interact with chromosomal rearrangements (inversions and translocations) [19] [20] [21] [22] [23] and decrease the fertility of their carriers [10]. The review [6] comprehensively describes the methods used for recovery, maintenance in culture, and properties of the conditional mutations and infers that the recovered conditional mutations meet the a priori expectations that these mutations are regulatory and are responsible for formation of the intraspecific similarity characters. Conditional mutations demonstrate a novel type of gene interaction when the interacting genes reside in parents, whereas the interaction event takes place in their progenies lacking these genes [24] [25].

The discovered properties of conditional mutations allow us to move on, from manifestation of mutations to the specificities of mutated genes and their role in ontogenesis. The goal of this work is to suggest a logically strict transition from the phenomenology of conditional mutations to the concept of ontogene, the specialized genetic unit responsible for regulation. We consider the parts of phenomenology of conditional mutations that allow for this transition, namely, 1) the effect of chromosomal rearrangements on the manifestation of conditional mutations; 2) the phenomenon of decreased fertility in carriers of conditional mutations; 3) a paternal form of the parental effect of conditional mutations; as well as 4) some properties of the chromosomal rearrangements that unite them with the conditional mutations.

\section{Materials and Methods}

The work has been performed with Drosophila melanogaster. The collection of conditional mutations was obtained earlier [10]. The conditional mutations in the $\mathrm{X}$ chromosome as well as chromosomes 2 and 3 [18] were used in experiments. Initially, the effects of chromosomal rearrangements on manifestation of conditional mutations were studied followed by studying the fertility of conditional mutants. Once the effect of chromosomal rearrangements on manifestation of conditional mutations was demonstrated, the genetic manifestations of themselves rearrangements were studied.

\subsection{The Effects of Chromosomal Rearrangements on the Manifestation of Conditional Mutations}

First, the mutations in the $\mathrm{X}$ chromosome were studied as conditional mutations. A "conditional" character of a mutation consisted in that it did not change the male phenotype and viability but acted as a dominant lethal in yellow/ + female [10]. The mutations were maintained in the stocks containing: 1) $+/$ In(1)Muller-5, $B w^{2}$ females; 2) In(1)Muller-5, $B w^{7} / \operatorname{In}(1)$ Muller-5, $B w^{3}$ females; 3) In(1)Muller-5, $B W^{2}$ males; and 4) (+) males. The (+) X chromosome carried the conditional mutation. 


\subsubsection{Chromosomal Rearrangements in the $X$ Chromosome}

The effect of a rearrangement can be regarded either as the effect of rearrangement itself as a permutation of chromosome blocks or as the effect of a set of alleles in the rearranged chromosome. In order to exclude the latter variant, the rearrangements were generated in the yellow control strain. This strain had earlier served for detection of conditional mutations in the $\mathrm{X}$ chromosome.

Male yellow flies were exposed to gamma-radiation and crossed with the $y e c$ $c t c V v f$ females carrying a set of mutations in the $\mathrm{X}$ chromosome. The heterozygous daughters were individually tested with yellow males to detect the cases when crossing over between the marker $\mathrm{X}$ chromosome and irradiated yellow chromosome was absent. The yellow sons were co-cultivated with the females carrying linked $\mathrm{X}$ chromosomes to determine the presence of a rearrangement in polytene chromosome preparations. The following rearrangements were obtained in the X chromosome of yellow strain: 1) inversion $\operatorname{In}(1) 5=\operatorname{In}(1) 6 F-7 A B$; $19 E-F ; 2)$ inversion $\operatorname{In}(1) 23=\operatorname{In}(1) 4 D-6 A C$; translocation $T(1 ; 2) 12=T(1 ; 2) 4 F$; $98 D$; and translocation $T(1 ; 2) 19=T(1 ; 2) 2 B-C ; 59 C$. For the experiment, the female heterozygotes carrying half autosomal set of yellow strain, normal $\mathrm{X}$ chromosome, and rearranged X chromosome from yellow strain were produced. The females of the above listed five strains (four strains with rearrangements and one control strain) were crossed with mutant $(+)$ males of ten strains (nos. $1-36)$.

\subsubsection{Chromosomal Rearrangements in Chromosomes 2 and 3}

The mutant $(+)$ males of strains nos. 1-34, carrying conditional mutations in the $\mathrm{X}$ chromosome were crossed to the yellow females of four genotypes:

1) $\mathrm{y} / \mathrm{y} ;+/+;+/+$;

2) $\mathrm{y} / \mathrm{y} ; \operatorname{In}(2 \mathrm{LR}) \mathrm{CyO} /+;+/+$;

3) $\mathrm{y} / \mathrm{y} ; \operatorname{In}(2 L R) P m /+;+/+$; and

4) $\mathrm{y} / \mathrm{y} ;+/+; \operatorname{In}(2 L R) D /+$.

The females of these genotypes were produced in the following way. The yellow females $\mathrm{y} / \mathrm{y} ;+/+;+/+$, earlier used for testing the conditional mutations in the $\mathrm{X}$ chromosome, were crossed with the males $\operatorname{In}(2 L R) P m / I n(2 L R) C y O$; $\operatorname{In}(2 L R) D / S b$. The males $y$; In $(2 L R) P m /+; \operatorname{In}(2 L R) D /+$ and $y, \operatorname{In}(2 L R) C y O /+$; $\operatorname{In}(2 L R) D /+$ were again crossed with the females of the initial strain $y / y,+/+$; $+/+$. The offspring of the cross contained the yellow females of all the necessary genotypes. The females differed only in the rearranged chromosomes. Females 1) were identical to those used for selection of mutants; females 2) differed from the latter by the presence of inverted chromosome $\mathrm{CyO}$; females 3), by the presence of inverted chromosome $\mathrm{Pm}$; and so on.

\subsubsection{The Effect of $\operatorname{In}(2 L R)$ Plum Inversion on the Manifestation of the Conditional Mutation <Small Barrel $>$ in Chromosome 2}

The mutation < Small barrels or Smba (Figure 1) was generated by gamma-irradiation and selected using the method of morphoses [26]. This mutation 

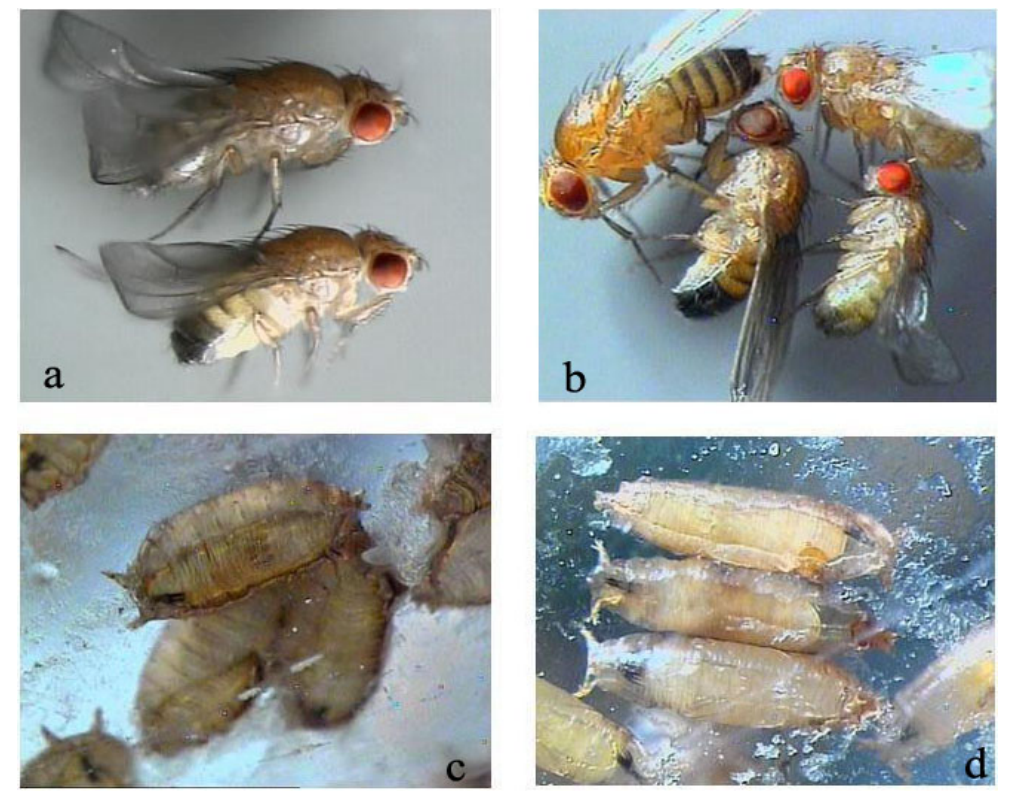

Figure 1. Mutation <Small barrel> (Smba): (a) general appearance of a mutant female and a male in the stock $\operatorname{Smbal} \operatorname{In}(2 L R) C y$, (b) left, female and male in stock $S m b a / \operatorname{In}(2 L R) P m$ (body size normal); right, female and male in the stock $S m b a / \operatorname{In}(2 L R) C y$ (body size reduced); (c) short pupae of stock $S m b a / \operatorname{In}(2 L R) C y$; (d) pupe of normal size of stock $\operatorname{Smba} \operatorname{In}(2 L R) P m$.

is dominant and lethal in homozygote. The adult males and females as well as the pupae have a shortened body. The manifestation of this mutation depends on the genotype of the strain [6]. The effect of two rearrangements in chromosome 2-inversion In (2LR) $P m$ and inversion $I n(2 L R) C y O$-on Smba manifestation was analyzed.

\subsubsection{The Effect of $\operatorname{In}(2 L R) C y O$ Inversion on the Manifestation of Conditional Mutations in Opposite Chromosome 2}

The method for recovering conditional mutations in chromosome 2 is based on testing the $2 / \operatorname{In}(2 L R) C y O$ males, carrying in the compound the irradiated $\mathrm{X}$ chromosome and inverted chromosome $\operatorname{In}(2 \mathrm{LR}) \mathrm{CyO}$, with the help of yellow females. The irradiated chromosome 2 with mutation $\left(2^{\star}\right)$ survived in the $2^{\star} / \operatorname{In}(2 L R) C y O$ offspring and failed to survive in the $2^{\star} / 2$ offspring [18] [20].

\subsection{The Phenomenon of a Decrease in Fertility in the Carriers of Conditional Mutations}

\subsubsection{Decrease in Male Fertility in the Individuals Carrying Conditional Mutations in the $\mathrm{X}$ Chromosome}

The signs suggesting a decrease in the male fertility in the presence of a conditional mutation became evident as early as the stage of mutant selection. The tubes with the absence of $(+)$ daughters simultaneously contained an unexpectedly low number of yellow sons in the offspring. After the recovered mutants were brought into culture, the mutant males were specially tested for fertility.

The $(+)$ males from each culture were individually crossed to the 3-day-old 
yellow females. After 3 days, the tubes bearing signs of emerged larvae were selected. The parents from these tubes were grouped to record egg laying. The egg laying continued in plug tubes with a standard medium until each tube contained 100 - 200 eggs. After at least 500 eggs per mutation were laid, the parents were removed and the tubes were placed into a thermostat at a temperature of $24^{\circ} \mathrm{C}$ until emergence of imagoes. The share of the eggs that developed to the adult stage among all the laid eggs was determined.

The mortality rate of the offspring in the same cross ( ㅇ y yellow $\times \hat{\delta}+$ ) was determined for each stage (white egg, brown egg, larva, pupa, and imago). The sample of laid ages was rather small, comprising 50 eggs.

\subsubsection{Qualitative Manifestations of a Decrease in Fertility}

It is not obligatory to count the laid eggs to make the inference on the fly fertility. A decrease in fertility is assessable according to the adult offspring. The absence of a certain phenotypic class or several classes in the offspring suggests a decrease in fertility as well as no offspring at all. Qualitative analysis of the offspring supplemented assessment of fertility in the carriers of conditional mutations.

\section{1) Reciprocal Crosses with Conditional Mutations in Chromosome 3}

Twelve reciprocal diallelic crosses involving four cultures of conditional $\mathrm{mu}$ tants in chromosome 3 (in total, 24 crosses) were conducted. Each of the conditional mutations (nos. 27, 34, 46, and 55) was maintained in the heterozygote with the inversion $\operatorname{In}(3 L R)$ Dichaete $=\operatorname{In}(3 L R) 71 F ; 85 C+\operatorname{In}(3 L R) 80 ; 84 A ; 93 F$ superimposed on $\operatorname{In}(3 L) 69 D 3-E 1 ; 70 C 13-D 1$. In the cultures of mutations, all individuals had a Dichaete phenotype. Theoretically, the offspring of two crossed cultures should comprise four phenotypic classes, namely, Dichaete males and females and Dichaete $^{+}$males and females.

2) The Response of Conditional Mutations to the Absence of the $Y$ Chromosome in Male Genome

In the norm, a D. melanogaster male contains the Y chromosome ( $X Y$ type) but also may lack it ( $X 0$ type). The $X 0$ type males are sterile. The mutant sons of both types were obtained from the males carrying a conditional mutation in the $\mathrm{X}$ chromosome. The cross with the females $C(1) D X, y w f l y$ gave mutant sons $X Y$ and the cross with the females $C(1) y / 0$, the mutant sons $X 0$. The shares of sons in the offspring allowed us to assess whether the presence of the $\mathrm{Y}$ chromosome influenced the viability of male zygote.

It is possible to obtain the mutant sons of $X Y$ and $X 0$ types in another way, from the mothers carrying a conditional mutation in a heterozygous condition. Such sons were obtained by crossing the females In(1)Muller-5, $W^{2} B /+$ with the $y$ males ( $X Y$ type) and $C(X Y), y B / 0$ males ( $X 0$ type). In this variant, the share of sons in the offspring was also determined. The data for the survival rate of the $X Y$ and $X 0$ males with conditional mutations were compared to the published data on the survival of $X Y$ and $X 0$ males carrying conventional mutations. 


\subsection{The Phenomenon of a Decrease in Fertility in the Carriers of a Chromosomal Rearrangement}

The yield of live offspring that emerged from the eggs of the pr pk cn females fertilized by the males with the flowing genotypes was estimated: 1)

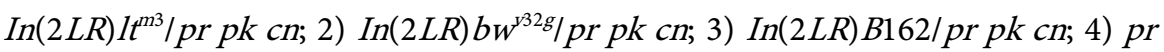
pk $c n / F(2 L) ; F(2 R)$, and 5) $\operatorname{In}(2 R) 40 / F(2 L) ; F(2 R)$. The males with genotypes (1)-(3) carried autosome 2 with one of the paracentric inversions $I n(2 L R) I t^{m 3}$, $\operatorname{In}(2 L R) b w^{\mathrm{r} 32 g}$ or $\operatorname{In}(2 L R) B 162$ and structurally normal autosome 2 . The inversions have the same boundaries: 1) $\operatorname{In}(2 L R) I^{m 3}=T(2 ; 4) I^{m 3}=T(2 ; 3) 40 ; 60 D$; $102 F ; 2) \operatorname{In}(2 L R) b W^{132 g}=\operatorname{In}(2 L R) 40 F ; 59 E ;$ and 3$) \operatorname{In}(2 L R) B 162=$ In $(2 L R) 36 E-59 D$. The pr pk $c n$ females carried structurally normal autosomes 2 with visible mutations purple, prickle, and cinnabar.

The males of the last two genotypes contained metacentric autosome 2, a normal and an inverted $(\operatorname{In}(2 R) 40)$, and two arm acrocentrics, $F(2 L)$ and $F(2 R)$, which replaced the second metacentric autosome 2 . The yields of viable offspring depending on the presence of the inversion $\operatorname{In}(2 R) 40=\operatorname{In}(2 R) 42 A-57 F$ in male metacentric autosome 2 were compared. In order to assess the yield of imagoes from the males with acrocentrics, each male was crossed to the females of four genotypes rather than a single one. The yield of imagoes was the sum of the estimates. The procedure how the total estimate was obtained is described in detail in the paper on segregation of the $D$. melanogaster chromosomes carrying acrocentric autosomes [27].

\subsection{Formation of Morphoses in the Offspring of Conditional Mutants: The Paternal Effect}

The individuals with morphoses appear in the offspring of conditional mutants [6] [13] [14]. The share of the progenies carrying morphoses varies from several to tens of percent [14]. The collection of images of morphoses, approaching a thousand of variants, contains a specific group of morphoses. A progeny carried a morphoses despite that it had not received the chromosome carrying a conditional mutation from its parent. Of special interest were the cases when morphoses were formed in the offspring of mutant males (paternal effect in inheritance of morphoses).

\section{Results}

\subsection{The Manifestation of Conditional Mutations: The Effect of Chromosomal Rearrangements}

\subsubsection{The Effects of Inversions and Translocations in the $X$ Chromosome}

The mutant males of wild-type phenotype (+) from 16 cultures (nos. 1-36) in the crosses with yellow females had almost no daughters in their offspring (Table 1, first column). The situation changed in the case of the yellow females with rearrangements (two inversions and two translocations) in their X chromosome: the 
Table 1. Removal of the lethal effect of conditional mutations in the $\mathrm{X}$ chromosome of male by rearrangements in the $\mathrm{X}$ chromosome of yellow female.

\begin{tabular}{|c|c|c|c|c|c|c|c|c|c|c|}
\hline \multirow{2}{*}{$\begin{array}{l}\text { Male } \\
\text { strain }\end{array}$} & \multicolumn{2}{|c|}{$\begin{array}{c}\text { Female } \\
\text { yly (controI) }\end{array}$} & \multicolumn{2}{|c|}{$\begin{array}{c}\text { Female } \\
\operatorname{In}(1) 5, y / y\end{array}$} & \multicolumn{2}{|c|}{$\begin{array}{c}\text { Female } \\
\text { In(1)23, } y / y\end{array}$} & \multicolumn{2}{|c|}{$\begin{array}{c}\text { Female } \\
T(1 ; 2) 12, y / y\end{array}$} & \multicolumn{2}{|c|}{$\begin{array}{c}\text { Female } \\
T(1 ; 2) 19, y / y\end{array}$} \\
\hline & $\begin{array}{l}\text { Total number } \\
\text { of progenies }\end{array}$ & $\begin{array}{l}\text { Rate of } \\
\text { females }\end{array}$ & $\begin{array}{l}\text { Total number } \\
\text { of progenies }\end{array}$ & $\begin{array}{l}\text { Rate of } \\
\text { females }\end{array}$ & $\begin{array}{l}\text { Total number } \\
\text { of progenies }\end{array}$ & $\begin{array}{l}\text { Rate of } \\
\text { females }\end{array}$ & $\begin{array}{c}\text { Total number } \\
\text { of progenies }\end{array}$ & $\begin{array}{l}\text { Rate of } \\
\text { females }\end{array}$ & $\begin{array}{l}\text { Total number } \\
\text { of progenies }\end{array}$ & $\begin{array}{l}\text { Rate of } \\
\text { females }\end{array}$ \\
\hline 1 & 191 & 0.00 & 169 & 0.06 & 87 & 0.01 & 138 & 0.01 & 148 & 0.03 \\
\hline 2 & 435 & 0.00 & 236 & 0.12 & 76 & 0.11 & 38 & 0.05 & 173 & 0.13 \\
\hline 3 & 180 & 0.00 & 469 & 0.63 & 190 & 0.43 & 128 & 0.59 & 331 & 0.58 \\
\hline 4 & 293 & 0.00 & 209 & 0.08 & 162 & 0.04 & 86 & 0.00 & 213 & 0.08 \\
\hline 5 & 303 & 0.02 & 107 & 0.27 & 112 & 0.01 & 46 & 0.04 & 96 & 0.22 \\
\hline 6 & 283 & 0.02 & 136 & 0.23 & 106 & 0.23 & 64 & 0.00 & 112 & 0.25 \\
\hline 26 & 89 & 0.01 & 121 & 0.24 & 210 & 0.30 & 46 & 0.02 & 69 & 0.28 \\
\hline 27 & 93 & 0.00 & 123 & 0.05 & 117 & 0.02 & 79 & 0.00 & 79 & 0.06 \\
\hline 29 & 61 & 0.00 & 203 & 0.49 & 122 & 0.57 & 18 & 0.00 & 128 & 0.55 \\
\hline 30 & 115 & 0.00 & 142 & 0.38 & 100 & 0.17 & 93 & 0.09 & 106 & 0.19 \\
\hline 31 & 83 & 0.00 & 118 & 0.19 & 123 & 0.22 & 121 & 0.04 & 195 & 0.27 \\
\hline 32 & 117 & 0.00 & 183 & 0.13 & 101 & 0.19 & 80 & 0.14 & 117 & 0.35 \\
\hline 33 & 90 & 0.00 & 144 & 0.34 & 123 & 0.24 & 42 & 0.17 & 100 & 0.22 \\
\hline 34 & 110 & 0.00 & 115 & 0.25 & 71 & 0.07 & 31 & 0.29 & 41 & 0.15 \\
\hline 36 & 110 & 0.01 & 108 & 0.25 & 127 & 0.20 & 105 & 0.01 & 323 & 0.46 \\
\hline
\end{tabular}

share of daughters in the offspring of (+) males only in rare cases remained low, approaching the expected estimate of 0.5 in the majority of cases. The fact that the rearrangements in female chromosomes were produced based on the yellow strain excludes the possibility that a change in the $\mathrm{X}$ chromosome gene composition was the cause of the observed effect.

\subsubsection{The Effect of Inversions in Chromosomes 2 and 3}

The mutant male of wild-type phenotype (+) from 11 cultures (nos. 1-34) in the crosses with yellow females had almost no daughters in their offspring (Table 2, first column). The situation changed in the case of the yellow females carrying the $C y$ or $P m$ inversions in chromosome 2. Inversion $D$ in chromosome 3 also manifested its effect but only in the case of mutations nos. 29, 33, and 34 .

\subsubsection{The Effect of Inversion $\operatorname{In}(2 L R) C y O$ on Survival of the Individual Carrying Mutation in the Opposite Chromosome 2}

The effects of chromosomal rearrangements on manifestation of the conditional mutations in the $\mathrm{X}$ chromosome was for the first time observed in the crosses mutant $(+)$ males to In(1)Muller-5/y females. The offspring of these females contained the In(1)Muller-5/+ daughters and $y /+$ daughters [20]. The ability of rearrangements to alter the manifestation of conditional mutations was utilized 
Table 2. Removal of the lethal effect of conditional mutation in the $\mathrm{X}$ chromosome of male by rearrangements in chromosomes 2 and 3 of yellow female (crosses of mutant males to the females: 1) $y / y,+/+($ control); 2) $y / y,+/ \operatorname{In}(2 L R) C y, 3) y / y ;+/ I n(2 L R) P m$ and 4) $y / y,+/ \operatorname{In}(3 L R) D)$.

\begin{tabular}{|c|c|c|c|c|c|c|c|c|c|c|c|c|c|c|}
\hline \multirow{3}{*}{$\begin{array}{l}\text { Male } \\
\text { mutant } \\
\text { strain }\end{array}$} & \multicolumn{2}{|c|}{ Female $y / y ;+/+$} & \multicolumn{4}{|c|}{ Female $y / y ;+/ C y$} & \multicolumn{4}{|c|}{ Female $y / y ;+/ P m$} & \multicolumn{4}{|c|}{ Female $y / y ;+l D$} \\
\hline & \multirow{2}{*}{ Daughter+ } & \multirow{2}{*}{$\begin{array}{c}\text { Son } \\
y\end{array}$} & \multicolumn{2}{|c|}{$\begin{array}{c}\text { Daughter } \\
+\end{array}$} & \multicolumn{2}{|c|}{$\begin{array}{c}\text { Son } \\
y\end{array}$} & \multicolumn{2}{|c|}{$\begin{array}{c}\text { Daughter } \\
+\end{array}$} & \multicolumn{2}{|c|}{$\begin{array}{c}\text { Son } \\
y\end{array}$} & \multicolumn{2}{|c|}{$\begin{array}{c}\text { Daughter } \\
+\end{array}$} & \multicolumn{2}{|c|}{$\begin{array}{c}\text { Son } \\
y\end{array}$} \\
\hline & & & $C y+$ & Cy & Cy+ & $C y$ & Pm+ & $P m$ & $P m+$ & $P m$ & $D^{+}$ & $D$ & $D^{+}$ & $D$ \\
\hline 1 & - & 230 & - & - & 178 & 163 & - & - & 107 & 57 & - & - & 115 & 8 \\
\hline 2 & - & 230 & 14 & 13 & 127 & 134 & 4 & 3 & 70 & 72 & - & - & 42 & 7 \\
\hline 4 & - & 270 & 9 & 4 & 185 & 159 & 1 & 7 & 86 & 81 & - & - & 162 & 7 \\
\hline 5 & - & 197 & 23 & 21 & 80 & 95 & 6 & 4 & 47 & 48 & - & - & 37 & 3 \\
\hline 27 & 2 & 167 & 1 & 0 & 102 & 113 & 2 & 1 & 53 & 65 & - & - & 9 & 2 \\
\hline 29 & 4 & 163 & 32 & 27 & 71 & 56 & 26 & 24 & 55 & 20 & 6 & 6 & 88 & 10 \\
\hline 30 & - & 184 & 15 & 13 & 81 & 76 & 9 & 12 & 60 & 47 & - & - & 38 & 6 \\
\hline 31 & - & 242 & 32 & 20 & 127 & 102 & 5 & 4 & 28 & 29 & - & - & 70 & 6 \\
\hline 32 & - & 197 & 22 & 10 & 90 & 77 & 9 & 17 & 36 & 32 & - & - & 48 & 2 \\
\hline 33 & - & 209 & 20 & 18 & 95 & 101 & 11 & 8 & 87 & 47 & 24 & 2 & 85 & 12 \\
\hline 34 & - & 140 & 11 & 14 & 88 & 101 & 25 & 20 & 68 & 54 & - & 10 & 103 & 3 \\
\hline
\end{tabular}

to design a method for recovering conditional mutations in chromosome 2. According to this method, a mutation in chromosome 2 could survive only if its opposite chromosome contained the inversion $\operatorname{In}(2 L R) C y O$. This method allowed for recovery of eight conditional mutations in chromosome 2. Table 3 shows that the paternal chromosome 2 carrying mutation $\left(2^{\star}\right)$ in compound with the normal maternal chromosome 2 fails to give viable offspring. Four of the eight mutants (nos. 5a-62a) produced a few such progenies. In the control strains, the ratio of (+) to $C y B I L^{4}$ classes did not differ from the expected value of 0.5. Thus, the inversion $\operatorname{In}(2 L R) C y O$ acted as a kind if "rescuer" of the conditional mutation in chromosome 2, proving for viability of the $2 * / \operatorname{In}(2 \mathrm{LR}) \mathrm{CyO}$, Cy BI L L heterozygotes.

\subsubsection{Maternal Effect of the Interaction between a Conditional Mutation and a Chromosomal Rearrangement}

The chromosomal rearrangements $\operatorname{In}(2 L R) C y O, \operatorname{In}(2 L R)$ Plum, and $\operatorname{In}(2 L R) D$ in the genome of yellow females caused emergence of a previously absent class of daughters (Table 2). Note that appearance of daughters was not associated with donation of the chromosomal rearrangement from mother: daughters could carry the rearrangement as well as could lack it (Table 2). Thus, a distinct maternal effect of rearrangement is evident. There is one more form of the maternal effect of a rearrangement. The inversion $\operatorname{In}(2 \mathrm{LR}) \mathrm{Cy} O$ from mother's side restores appearance of daughters in the offspring, whereas the same inversion from the side of a mutant $(+)$ male displays no such effect [20].

The described data do not embrace all obtained results concerning the effect of rearrangements on the manifestation of conditional mutations [19] [21] [22] 
Table 3. Progeny of the males carrying conditional dominant lethals in chromosome 2 (cross 우 $y \times$ of $2 * C y B I L^{4}$ ).

\begin{tabular}{ccccccc}
\hline \multirow{2}{*}{$\begin{array}{c}\text { Male mutant } \\
\text { strain }\end{array}$} & \multicolumn{2}{c}{ Progeny $2^{*}(+)$} & \multicolumn{2}{c}{ Progeny $C y B 1 L^{4}$} & $\begin{array}{c}\text { Total number } \\
\text { of progenies }\end{array}$ & $\begin{array}{c}\text { Rate of } \\
\text { progeny } 2^{*}(+)\end{array}$ \\
\cline { 2 - 6 } $7 \mathrm{a}$ & - & - & 116 & 110 & 226 & 0.00 \\
$37 \mathrm{a}$ & - & 1 & 124 & 130 & 254 & 0.00 \\
$44 \mathrm{a}$ & - & 1 & 125 & 109 & 234 & 0.00 \\
$53 \mathrm{a}$ & - & - & 101 & 130 & 231 & 0.00 \\
$5 \mathrm{a}$ & 11 & 6 & 146 & 140 & 303 & 0.06 \\
$8 \mathrm{a}$ & 6 & - & 135 & 98 & 239 & 0.03 \\
$9 \mathrm{a}$ & 9 & 9 & 96 & 84 & 198 & 0.09 \\
$62 \mathrm{a}$ & 1 & 1 & 154 & 144 & 300 & 0.01 \\
Control & & & & & & \\
42a & 111 & 139 & 135 & 120 & 505 & 0.51 \\
26a & 128 & 107 & 106 & 106 & 447 & 0.53 \\
\hline
\end{tabular}

${ }^{\star}$ Chromosome 2 carrying a conditional mutation.

but are sufficient to illustrate the important principles. First, the ability to influence the manifestation of conditional mutations is the common feature of chromosomal rearrangements, which alter the order of chromosome regions in the nuclear space. The rearrangements in the mutant genome possess this ability as well as the rearrangements in the partner genome. This ability distinguishes the genes that produce conditional mutations from the typical "Mendelian" genes. The latter as a rule do not respond to the presence of rearrangements in the genome. Second, the mechanisms underlying manifestations of a conditional mutation and a rearrangement should have a common link; otherwise, the mutations and rearrangements would not interact.

\subsection{The Manifestation of Conditional Mutations: A Decrease in Fertility}

\subsubsection{The Phenomenon of a Decrease in Fertility}

The major feature that gave the name to conditional mutations is their conditional nature, that is, the dependence of manifestation-non-manifestation on the genotype of an individual or its parents. The manifestation can be visible (altered phenotype of the individual) or lethal (death of offspring), the latter being prevalent. In the majority of cases, conditional mutations are conditional dominant lethals [4] [6].

The fact that a mutation results the absence of a particular phenotypic class in the offspring gives the grounds to refer to it as "conditional" mutation. However, missing of a certain class is also associated with fertility. Leaving particular classes missing in the offspring and the genotypes associated with this absence out of consideration, we see that a conditional mutation in general demonstrates 
the phenomenon of a decrease in fertility. Thus, the conditional manifestation is converted from an exotic phenomenon of "a conditional pattern of manifestation" to a more known although also vague in its nature phenomenon of disturbance in fertility. This allows the research into conditional mutations of drosophila to be supplemented by a traditional estimation of fertility as the ratio of emerged imagoes to the laid eggs.

In total, 21 male $(+)$ carrying a conditional mutation in the $\mathrm{X}$ chromosome were examined (Table 4). The table shows the progenies of each of the mutant males in the cross with yellow females. Each cross was performed in duplicate (with two and with six females). The offspring was almost exclusively represented by yellow sons. In addition to the absence of daughters, an extremely low fertility of males is observable: the rate of survived progenies for 17 males amounted to 2 - 19 instead of $100 \%$. The low fertility is unexplainable with the absence of daughters. Even when the daughters are absent at all, the male fertility cannot be less than $50 \%$.

Another experiment showed a low fertility of the males with a conditional mutation in the $\mathrm{X}$ chromosome (Table 5). Zygotes died mainly during embryonic development (white eggs) and very rarely, at the stages of larva and pupa.

\subsubsection{Qualitative Forms of the Phenomenon of Decreased Fertility}

As is described above, a decreased fertility of conditional mutants is suggested by the absence of an expected class of progenies or a lower size of a certain class relative to the expected value.

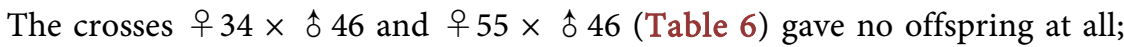
however, reciprocal crosses gave the offspring. The crosses $+55 \times \hat{\delta} 34$ and 우 $34 \times\left\{55\right.$ lacked half progenies that had the phenotype Dichaete ${ }^{+}$, while the other half, with the Dichaete phenotype, was present. As for the remaining three pairs of crosses, the fertility of direct crosses (first row in the pair) was lower owing to deficiency in the Dichaete class. The decrease in viability of the Dichaete class because of the presence of the Dichaete mutation was out of question, since the Dichaete individuals were abundant in the reciprocal crosses (second row in the pair).

This suggests that

1) A decrease in fertility is the major property of a conditional mutation;

2) "Conditionality" is only a specific form of the decrease in fertility manifesting as the absence of a certain class of progenies ("selective lethality"); and

3) Selective lethality of the offspring depends on the genotypes of both parents; the deviations in the ratio of phenotypic classes of the progenies cannot be explained by the viability of the visible mutations marking the corresponding classes.

\subsubsection{Paternal Effect of Decreased Fertility}

As is shown above, the decrease in fertility takes place in both sexes. In this section, the phenomenon of decreased fertility is considered for males. As will be 
Table 4. Progeny of the mutant males (+) in crosses with yellow females.

\begin{tabular}{|c|c|c|c|c|c|}
\hline \multirow{2}{*}{$\begin{array}{l}\text { Male mutant } \\
\text { strain }\end{array}$} & \multicolumn{2}{|c|}{ Cross $2+y \times \partial^{\lambda}+$} & \multicolumn{2}{|c|}{ Cross $6+y \times \partial^{\lambda}+$} & \multirow[b]{2}{*}{ Male fertility } \\
\hline & $\begin{array}{l}\text { Total number of } \\
\text { progenies }\end{array}$ & $\begin{array}{c}\text { Rate of } \\
\text { daughters }\end{array}$ & $\begin{array}{c}\text { Total number of } \\
\text { progenies }\end{array}$ & $\begin{array}{c}\text { Rate of } \\
\text { daughters }\end{array}$ & \\
\hline 1 & 119 & 0.00 & 191 & 0.00 & 0.02 \\
\hline 2 & 650 & 0.00 & 435 & 0.00 & 0.15 \\
\hline 3 & 112 & 0.00 & 180 & 0.00 & 0.12 \\
\hline 4 & 114 & 0.00 & 293 & 0.00 & 0.07 \\
\hline 5 & 50 & 0.00 & 303 & 0.02 & 0.14 \\
\hline 6 & 47 & 0.00 & 283 & 0.02 & 0.14 \\
\hline 7 & 47 & 0.02 & 100 & 0.00 & - \\
\hline 9 & 182 & 0.07 & 529 & 0.00 & 0.40 \\
\hline 10 & 162 & 0.03 & 297 & 0.04 & 0.09 \\
\hline 27 & 68 & 0.00 & 93 & 0.00 & 0.18 \\
\hline 29 & 15 & 0.07 & 61 & 0.00 & 0.14 \\
\hline 30 & 122 & 0.00 & 115 & 0.00 & 0.19 \\
\hline 31 & 106 & 0.00 & 83 & 0.00 & 0.15 \\
\hline 32 & 81 & 0.00 & 117 & 0.00 & 0.13 \\
\hline 33 & 144 & 0.00 & 90 & 0.00 & 0.16 \\
\hline 34 & 88 & 0.00 & 110 & 0.00 & 0.12 \\
\hline 26 & 92 & 0.03 & 89 & 0.01 & - \\
\hline 35 & 102 & 0.03 & 115 & 0.04 & 0.35 \\
\hline 36 & 95 & 0.00 & 110 & 0.01 & 0.14 \\
\hline 37 & 52 & 0.02 & 68 & 0.04 & 0.14 \\
\hline 38 & 54 & 0.06 & 84 & 0.01 & 0.10 \\
\hline
\end{tabular}

*The male fertility is determined as the ratio of the number of imagoes that emerged from the eggs laid by yellow females crossed with the mutant males to the number of laid eggs.

demonstrated in Discussion, this phenomenon plays a crucial role in determining its true cause particularly in males. A decrease in fertility of mutant males followed a parental type (a paternal form of the parental effect).

The fertility of the $(+)$ males with conditional mutations in the $\mathrm{X}$ chromosome is drastically decreased (Table 4 and Table 5), amounting in individual cases to only several percent (Table 4, nos. 1, 4, and 10; Table 5, nos. 2, 5, 8, 29, 30, 31, and 41 ). If all daughters died, the fertility of a male should be $50 \%$. However, it was lower, suggesting that yellow sons died as well. The yellow sons do not get the mutant $\mathrm{X}$ chromosome from their father. Only the presence of mutant chromosome in their father is sufficient for the lethality of sons. This is a parental effect of conditional mutation of a paternal type.

\subsubsection{The Response of Conditional Mutations to the Absence of $Y$ Chromosome in the Male Genome}

The conditional mutations in the $\mathrm{X}$ chromosome distinctly respond to the absence of the $\mathrm{Y}$ chromosome in the male genome (Table 7). If the share of the sons with $\mathrm{Y}$ chromosome $(X Y)$ approaches the expected rate of $0.5(\bar{x}=0.46)$, then the share of the sons without $\mathrm{Y}$ chromosome $(X 0)$ in the offspring most 
Table 5. Death of zygotes in crosses of yellow females with the males carrying conditional mutations in the $\mathrm{X}$ chromosome.

\begin{tabular}{|c|c|c|c|c|c|c|}
\hline \multirow{2}{*}{$\begin{array}{l}\text { Male mutant } \\
\text { strain }\end{array}$} & \multirow{2}{*}{$\begin{array}{c}\text { Total number } \\
\text { of laid eggs }\end{array}$} & \multicolumn{4}{|c|}{ Lethality at the stage of (\%) } & \multirow{2}{*}{$\begin{array}{c}\text { Live } \\
\text { imagoues (\%) }\end{array}$} \\
\hline & & White egg & Brown egg & Larva & Pupa & \\
\hline 1 & 50 & 92 & 2 & - & - & 6 \\
\hline 2 & 50 & 81 & 13 & 2 & - & 4 \\
\hline 3 & 50 & 76 & 18 & - & - & 6 \\
\hline 5 & 100 & 65 & 28 & 3 & - & 4 \\
\hline 6 & 50 & 80 & 8 & - & - & 12 \\
\hline 7 & 50 & 52 & 32 & 6 & 2 & 8 \\
\hline 8 & 50 & 90 & 6 & - & - & 4 \\
\hline 10 & 50 & 68 & 20 & 6 & - & 6 \\
\hline 11 & 50 & 56 & 30 & 2 & - & 12 \\
\hline 27 & 50 & 72 & 8 & 6 & - & 12 \\
\hline 29 & 50 & 92 & 6 & - & - & 2 \\
\hline 30 & 50 & 96 & 2 & 1 & - & - \\
\hline 31 & 50 & 90 & 4 & 2 & - & 4 \\
\hline 32 & 50 & 46 & 32 & 8 & - & 14 \\
\hline 33 & 50 & 50 & 28 & 6 & 2 & 14 \\
\hline 36 & 24 & 33 & 54 & - & 6 & 7 \\
\hline 38 & 40 & 68 & 22 & 5 & - & 5 \\
\hline 41 & 50 & 90 & 6 & - & - & 4 \\
\hline Average & 51 & 72 & 18 & 3 & 0.6 & 7 \\
\hline
\end{tabular}

Table 6. The rate of Dichaete progenies in reciprocal crosses of four lines Dichaete/ $C D L(3),+($ nos. $27,34,46$, and 55$)$ containing conditional mutations in chromosome $3^{*}$.

\begin{tabular}{|c|c|c|c|c|c|c|c|c|}
\hline \multirow{3}{*}{$\begin{array}{l}\text { Reciprocal } \\
\text { crosses }\end{array}$} & \multicolumn{6}{|c|}{ Progeny } & \multirow{3}{*}{$\begin{array}{c}\text { Total } \\
\text { number of } \\
\text { progenies }\end{array}$} & \multirow{3}{*}{$\begin{array}{c}\text { Dichaete } \\
\text { progenies } \\
(\%)\end{array}$} \\
\hline & \multicolumn{3}{|c|}{ Dichaete $^{+}$} & \multicolumn{3}{|c|}{ Dichaete } & & \\
\hline & Females & Males & Total & Females & Males & Total & & \\
\hline$+27 \times 33$ & 49 & 47 & 96 & 20 & 13 & 33 & 129 & 25.58 \\
\hline q $34 \times \overbrace{}^{\top} 27$ & 56 & 41 & 97 & 114 & 67 & 181 & 278 & 65.11 \\
\hline$+27 \times \jmath^{7} 46$ & 132 & 147 & 279 & 34 & 31 & 65 & 344 & 18.90 \\
\hline 우 $46 \times 327$ & 63 & 68 & 131 & 102 & 135 & 237 & 368 & 64.40 \\
\hline 우 $27 \times \widehat{3} 55$ & 88 & 158 & 246 & 29 & 28 & 57 & 303 & 18.81 \\
\hline 우 $55 \times 327$ & 37 & 30 & 67 & 97 & 59 & 156 & 223 & 70.00 \\
\hline $934 \times \delta 46$ & 0 & 0 & 0 & 0 & 0 & 0 & 0 & 0 \\
\hline 우 $46 \times \overbrace{}^{\top} 34$ & 73 & 95 & 168 & 109 & 95 & 204 & 372 & 54.80 \\
\hline q $46 \times ð 55$ & 145 & 166 & 311 & 264 & 279 & 543 & 854 & 63.60 \\
\hline 우 $55 \times \overbrace{}^{\lambda} 46$ & 0 & 0 & 0 & 0 & 0 & 0 & 0 & 0 \\
\hline 우 $55 \times \overbrace{}^{\top} 34$ & 0 & 0 & 0 & 81 & 65 & 146 & 146 & 100 \\
\hline$q 34 \times \overbrace{}^{\lambda} 55$ & 0 & 0 & 0 & 114 & 91 & 205 & 205 & 100 \\
\hline
\end{tabular}

${ }^{\star}$ In each $C D L(3) / \operatorname{In}(3 L R)$ Dichaete strain, only the heterozygotes for $C D L(3)$ and $\operatorname{In}(3 L R)$ Dichaete are viable. $C D L(3)$ is a conditional dominant lethal in chromosome 3. 
Table 7. Influence of the Y chromosome on the lethal effect of conditional mutation received by son from its father.

\begin{tabular}{|c|c|c|c|c|}
\hline \multirow{2}{*}{$\begin{array}{c}\text { Male } \\
\text { mutant strain }\end{array}$} & \multicolumn{2}{|c|}{ Cross: $q C(1)$ yw $f / Y \times \partial^{\lambda}+$} & \multicolumn{2}{|c|}{ Cross : $+\boldsymbol{C}(1) \mathrm{y} / \mathbf{0} \times \widehat{\partial}+$} \\
\hline & $\begin{array}{l}\text { Total number of } \\
\text { progenies }\end{array}$ & $\begin{array}{c}\text { Rate of } X Y \text { males in the } \\
\text { progeny }\end{array}$ & $\begin{array}{l}\text { Total number of } \\
\text { progenies }\end{array}$ & $\begin{array}{c}\text { Rate of } X 0 \text { males in } \\
\text { the progeny }\end{array}$ \\
\hline 1 & 51 & 0.35 & 131 & 0.02 \\
\hline 2 & 42 & 0.60 & 118 & 0.05 \\
\hline 3 & 33 & 0.39 & 90 & 0.05 \\
\hline 4 & 85 & 0.38 & 137 & 0.00 \\
\hline 5 & 8 & 0.25 & 97 & 0.12 \\
\hline 6 & 133 & 0.50 & 37 & 0.03 \\
\hline 7 & 37 & 0.57 & 142 & 0.12 \\
\hline 8 & 19 & 0.47 & 123 & 0.16 \\
\hline 9 & 199 & 0.55 & 123 & 0.05 \\
\hline 10 & 30 & 0.40 & 107 & 0.14 \\
\hline 11 & 152 & 0.51 & 95 & 0.13 \\
\hline 13 & 61 & 0.49 & 54 & 0.09 \\
\hline 15 & 82 & 0.50 & 70 & 0.20 \\
\hline Total & 932 & $\bar{x}=0.46$ & 1324 & $\bar{x}=0.09$ \\
\hline
\end{tabular}

likely will tend to zero $(\bar{x}=0.09)$. This pattern is characteristic of all $13 \mathrm{ex}-$ amined mutations in the case if mutant sons receive the mutant $\mathrm{X}$ chromosomes from their fathers (Table 7).

In the case when sons receive the mutant $\mathrm{X}$ chromosomes from their mothers (Table 8), the absence of the $\mathrm{Y}$ chromosome ceases influencing their share in the offspring. The average share of the mutant sons with $Y$ chromosome $(X Y)$ in the offspring of a mutant female is 0.18 and of the mutant sons lacking $\mathrm{Y}$ chromosome $(X 0), 0.21$. A pairwise comparison for each of the examined 19 mutations demonstrates the absence of the above difference between the $X Y$ and $X 0$ classes.

For simplicity of understanding of the result, the data on the mutant $X Y$ and $X 0$ males in Table 9 are given in a general form. The (+) sign denotes the presence of mutant males in the offspring and (-), their absence or the presence in an extremely low number. The data of the experiment with the males carrying conditional mutations in their $\mathrm{X}$ chromosome (the last rows in table) are compared to the results known from the classical genetic literature on inheritance of visible mutations in the $\mathrm{X}$ chromosome and standard recessive lethals in the $\mathrm{X}$ chromosome.

The D. melanogaster males carrying recessive visible mutations in the $\mathrm{X}$ chromosome can be produced in both direct and reciprocal crosses of the corresponding cultures. The absence of the $\mathrm{Y}$ chromosome, as is known from the literature, influences only male fertility but not their viability [28]. Thus, the recessive visible mutations in Table 9 are denoted with $(+)$ in each of the four 
Table 8. Influence of the Y chromosome on the lethal effect of conditional mutation received by son from its mother*.

\begin{tabular}{|c|c|c|c|c|}
\hline \multirow{2}{*}{$\begin{array}{l}\text { Male mutant } \\
\text { strain }\end{array}$} & \multicolumn{2}{|c|}{$\begin{array}{c}\text { Cross } \\
\text { } \operatorname{In}(1) \text { Muller }-5, w^{2} B l+\times \partial y\end{array}$} & \multicolumn{2}{|c|}{$\begin{array}{c}\text { Cross } \\
\text { †n(1)Muller-5, } w^{2} B l+\times ð C(X Y), y B / C\end{array}$} \\
\hline & $\begin{array}{l}\text { Total number of } \\
\text { progenies }\end{array}$ & $\begin{array}{l}\text { Rate of } X Y,+ \text { males } \\
\text { in the progeny }\end{array}$ & $\begin{array}{l}\text { Total number of } \\
\text { progenies }\end{array}$ & $\begin{array}{c}\text { Rate of } X 0,+ \text { males in } \\
\text { the progeny }\end{array}$ \\
\hline 2 & 317 & 0.10 & 103 & 0.13 \\
\hline 3 & 122 & 0.19 & 15 & 0.13 \\
\hline 5 & 242 & 0.22 & 122 & 0.26 \\
\hline 6 & 501 & 0.15 & 156 & 0.19 \\
\hline 7 & 377 & 0.18 & 117 & 0.33 \\
\hline 8 & 363 & 0.25 & 192 & 0.30 \\
\hline 9 & 250 & 0.12 & 139 & 0.10 \\
\hline 10 & 194 & 0.23 & 182 & 0.25 \\
\hline 11 & 291 & 0.22 & 170 & 0.29 \\
\hline 29 & 285 & 0.21 & 307 & 0.11 \\
\hline 30 & 378 & 0.15 & 165 & 0.19 \\
\hline 31 & 460 & 0.17 & 121 & 0.21 \\
\hline 32 & 226 & 0.19 & 89 & 0.21 \\
\hline 33 & 162 & 0.14 & 205 & 0.22 \\
\hline 34 & 264 & 0.10 & 193 & 0.01 \\
\hline 35 & 444 & 0.08 & 184 & 0.10 \\
\hline 36 & 481 & 0.21 & 221 & 0.28 \\
\hline 38 & 504 & 0.24 & 138 & 0.24 \\
\hline 41 & 359 & 0.23 & 227 & 0.39 \\
\hline Total & 6220 & $\bar{x}=0.18$ & 3046 & $\bar{x}=0.21$ \\
\hline
\end{tabular}

${ }^{*}$ Mutation in the X chromosome (+).

Table 9. Survival of $X 0$ and $X Y$ males depending on the type of mutation in the $\mathrm{X}$ chromosome and the donor of mutation ${ }^{*}$.

\begin{tabular}{cccc}
\hline Type of mutation in X chromosome & Chromosomal type of son & \multicolumn{2}{c}{ Donor of X mutation } \\
\cline { 2 - 3 } Mendelian visible & $X Y$ & Mother & Father \\
\hline Mendelian lethal & $X 0$ & + & + \\
& $X Y$ & - & - \\
& $X 0$ & - & + \\
Conditional lethal & $X Y$ & + & + \\
\hline
\end{tabular}

${ }^{*}(+)$ denotes the presence of sons and $(-)$, the absence of sons or their extremely low number. 
cells. Unlike the $D$. melanogaster males carrying visible mutations, the males carrying recessive lethal mutations in their $\mathrm{X}$ chromosome do not emerge in both the direct and recessive crosses [28]. The presence or absence of the $Y$ chromosome in this case does not matter. The recessive lethals in Table 9 are denoted with (-) in each of the four cells. Table 9 demonstrates that the conventional mutations despite the differences between them (lethal and not lethal) according to $X Y-X 0$ test react to neither the cross direction nor the presence of $\mathrm{Y}$ chromosome. Unlike the conventional mutations, the conditional mutations are sensitive to both factors.

\subsection{The Manifestation of Conditional Mutations: Appearance of Morphoses (Paternal Effect)}

The conditional mutations in the laboratory collection were maintained as heterozygotes. Half offspring of a heterozygote receives the mutation and the other half does not. Nonetheless, morphoses emerged not only in the progenies that got the mutation, but also in the progenies lacking it. In the cross of a yellow female with the mutant $(+)$ male carrying a conditional mutation in the $\mathrm{X}$ chromosome, the yellow sons did not get the mutant $\mathrm{X}$ chromosome but still part of them formed morphoses (Figure 2). In the cross of $C(1) D X, y w f$ females with the $(+)$ males carrying a conditional mutation in the $\mathrm{X}$ chromosome, the $C(1) D X, y w$ daughters did not get the mutant $\mathrm{X}$ chromosome but part of the daughters displayed morphoses (Figure 2(f), Figure 2(i)). Thus, it is sufficient for a progeny to form a morphosis that its father carries a conditional mutation and is unnecessary to get the mutation itself from the father. The parental inheritance as a paternal effect is thus evident.

One of the ways to maintain conditional mutations in the $\mathrm{X}$ chromosome was to keep them in the females heterozygous for the inverted chromosome In(1)Muller-5, $B \quad W^{2}$. In the culture Muller-5/mutation, the females In(1)Muller-5, $B W^{2} / \operatorname{In}(1)$ Muller-5, $B W^{2}\left(B W^{2}\right.$ phenotype) and the males In(1)Muller-5, $B W^{2}$ ( $B W^{2}$ phenotype) did not carry conditional mutation; however, some of them had morphoses (Figure 3 ). This is also the case when a progeny did not necessarily have to carry the chromosome with conditional mutation to develop a morphosis. It was sufficient that such a mutation was present in the mother. A parental type of inheritance took place in this case as well but in a maternal variant. The daughters $B W^{2}$ and the sons $B W^{2}$ with morphoses developed from the eggs that did not contain any conditional mutation in the $\mathrm{X}$ chromosome.

\subsection{The Manifestation of Chromosomal Rearrangements: A Decrease in Fertility (Paternal Effect)}

As to the chromosomal rearrangements, it has appeared that they not only alter the manifestation of conditional mutations, but also themselves act as like conditional mutations. The chromosomal rearrangements decrease fertility of the carriers, and this decrease follows a parental type. Four inversions in chromosome 

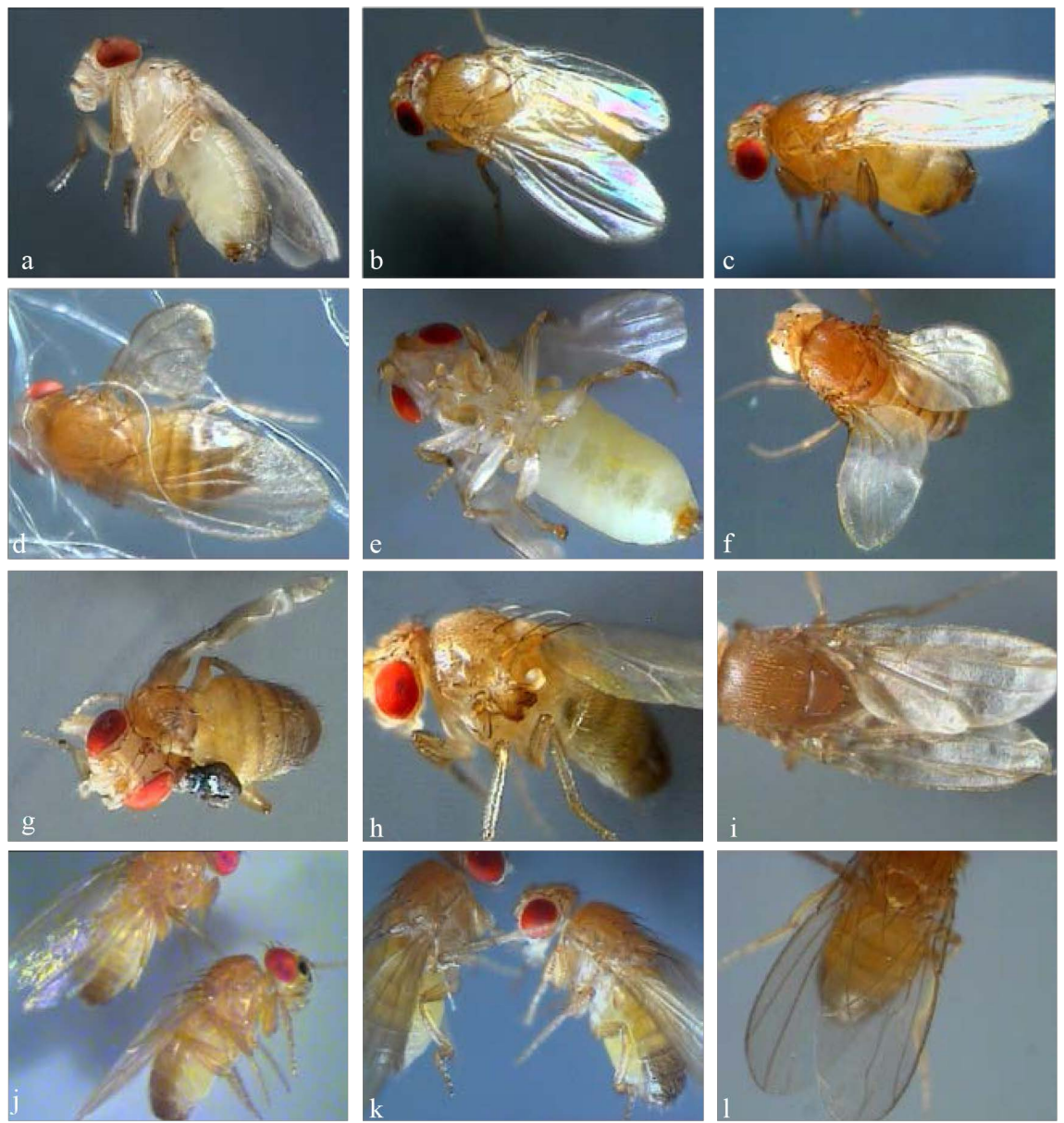

Figure 2. Morphoses in the offspring of conditional mutants. I. Parental effect of a paternal type. Conditional mutation was in the $\mathrm{X}$ chromosome of a normal male crossed to yellow females. The yellow sons did not receive the mutant chromosome from their father but still developed morphoses. In two cases, a male was crossed to the $C(1) D X, y w f$ females. The $y w f$ daughters (f) and (i) did not get the mutant $\mathrm{X}$ chromosome from their father but had morphoses. The morphoses included (a) the absence of the left metathoracic leg; (b) shortened right wing; (c) altered tergite pattern from the left side; (d) altered shape of the right wing; (e) absent tarsus in the right metathoracic leg and changed shape of this leg; ( $\mathrm{f}$ ) altered wing shape and structure; ( $\mathrm{g}$ ) reduction of the left thorax and left wing; (h) left wing replaced with two appendages; (i) reduction of the left wing; (j) myeloma of the right arista in the lower male; $(\mathrm{k})$ shortened and deformed tibia of the metathoracic legs in males; and (l) impaired wing veining.

2- $\operatorname{In}(2 L R) I t^{m 3}, \operatorname{In}(2 L R) b w^{\mathrm{r} 32 g}, \operatorname{In}(2 L R) B 162$, and $\operatorname{In}(2 R) 40$-decrease the male fertility to $81-40 \%$ of the norm (Table 10 ). A high lethality rate of zygotes is not determined by low fertility of the progenies that received a particular inversion. The ratio of the number of progenies carrying the inversion to the number of progenies without it varied around the expected value of 50\% (Table 10, last column). Here, a paternal effect of decrease in fertility is evident: death of part of the offspring is the result of the rearrangement present in the parent (father) rather than in the progeny itself. Thus, the conditional mutations and chromosomal rearrangements display similarity in their manifestations. Both 

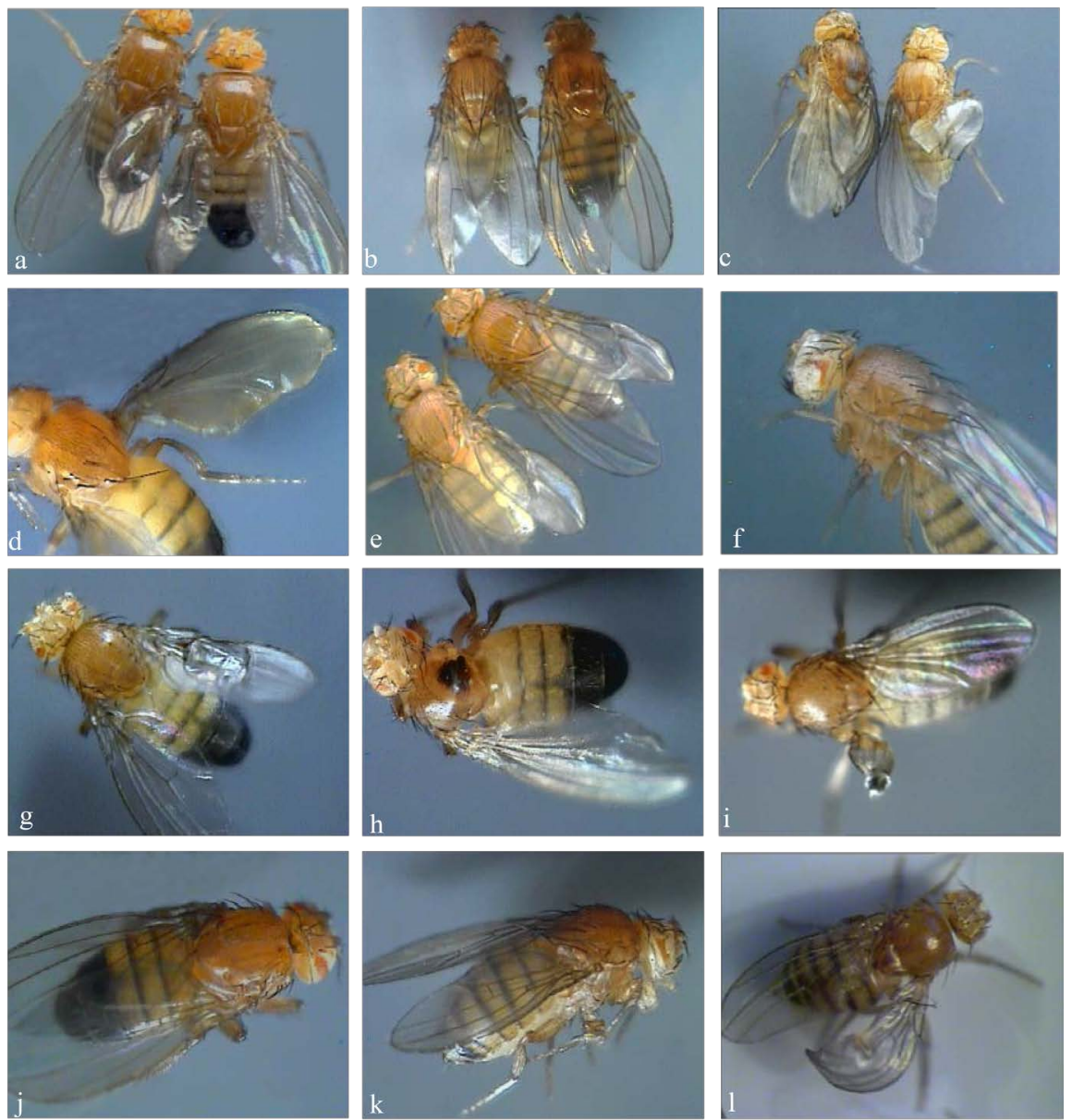

Figure 3. Morphoses in the offspring of conditional mutants. II. Parental effect of a maternal type. Conditional mutation was in the $\mathrm{X}$ chromosome (+) of a $+/ \operatorname{In}(1)$ Muller $-5, B$

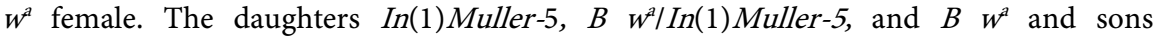
In(1)Muller-5, $B W^{2}$ with a $B W^{2}$ phenotype (bar-shaped apricot eyes) did not receive the $\mathrm{X}$ chromosome with conditional mutation from their mother but formed the following morphoses: (a) wings of different lengths with bubbles; (b) narrowed wing, impaired veining, and a bubble; (c) opaque wings of various shapes; (d) the right wing filled with lymph; impaired veining; (e) asymmetric wings; (f) tissue overgrowth instead of left eye ommatidia; ( $g$ ) reduced right wing with irregular shape and a bubble; (h) absent right wing; colored tissue in the thoracic base; (i) reduced wing blade from the left side; (j) absence of macrochaetes and microchaetes in the right side of the thorax; $(\mathrm{k})$ deformed femur of the right mesothoracic leg; and (l) sickle-shaped right wing.

decrease the fertility of their carriers, and this decrease takes place in the form of a parental (paternal) effect.

\section{Discussion}

\subsection{The Arguments in Favor of Existence of a Special Department in the Genetic System That Controls the Course of Individual Development}

The results suggest several inferences on the genetic elements giving rise to conditional mutations. 
Table 10. Decreased fertility of the males carrying a chromosomal rearrangement.

\begin{tabular}{|c|c|c|c|c|c|}
\hline Male genotype & $\begin{array}{c}\text { Female } \\
\text { genotype }\end{array}$ & $\begin{array}{l}\text { Number of } \\
\text { laid eggs }\end{array}$ & $\begin{array}{l}\text { Number of } \\
\text { emerged } \\
\text { imagoes }\end{array}$ & $\begin{array}{c}\text { Rate of } \\
\text { imagoes }\end{array}$ & $\begin{array}{c}\text { Rate of the progenies } \\
\text { with rearrangements } \\
\text { relative to their total } \\
\text { number }\end{array}$ \\
\hline $\begin{array}{l}\operatorname{In}(2 L R) l t^{m 3} \\
\text { prpk cn }\end{array}$ & pr pk cn & 1987 & 1066 & $48.5 \pm 5.4$ & 0.45 \\
\hline \multirow{4}{*}{$\begin{array}{l}\operatorname{In}(2 L R) b w^{r 32 g} / \\
\text { pr pkcn } \\
\operatorname{In}(2 L R) B 162 / \\
\text { pr pkcn }\end{array}$} & pr pk cn & 1990 & 1599 & $80.7 \pm 2.0$ & 0.50 \\
\hline & pr pk cn & 1405 & 538 & $40.5 \pm 5.9$ & 0.50 \\
\hline & 1) $\mathrm{pr} p \mathrm{pkn}$ & 2195 & 1631 & $73.7 \pm 3.0$ & 0.50 \\
\hline & $\begin{array}{l}\text { 2) } \mathrm{F}(2 \mathrm{~L}), \mathrm{pr} \\
\mathrm{C}(2 \mathrm{R}), \mathrm{cn}\end{array}$ & 2286 & 145 & $12.6 \pm 2.2$ & 0.42 \\
\hline \multirow[t]{5}{*}{$\begin{array}{c}\text { prpk cn/F(2L); } \\
F(2 R)^{*}\end{array}$} & $\begin{array}{l}\text { 3) } \mathrm{C}(2 \mathrm{~L}), \mathrm{b} \text {; } \\
\mathrm{F}(2 \mathrm{R}),+\end{array}$ & 2719 & 23 & $1.4 \pm 1.0$ & 0.52 \\
\hline & $\begin{array}{c}\text { 4) } \mathrm{C}(2 \mathrm{LR}) \mathrm{EN} \text {, } \\
\text { c bw }\end{array}$ & 2178 & 0 & 0.0 & - \\
\hline & Total & & & 87.7 & $\mathrm{x}=0.48$ \\
\hline & 1) $\mathrm{pr} \mathrm{pk} \mathrm{cn}$ & 2193 & 867 & $42.3 \pm 10.0$ & 0.51 \\
\hline & $\begin{array}{l}\text { 2) } \mathrm{F}(2 \mathrm{~L}), \mathrm{pr} \\
\mathrm{C}(2 \mathrm{R}), \mathrm{cn}\end{array}$ & 2325 & 22 & $2.0 \pm 0.3$ & 0.68 \\
\hline \multirow[t]{3}{*}{$\begin{array}{c}\operatorname{In}(2 R) 40 / F(2 L) \\
F(2 R)^{\star}\end{array}$} & $\begin{array}{c}\text { 3) } \mathrm{C}(2 \mathrm{~L}), \mathrm{b} \\
\mathrm{F}(2 \mathrm{R}),+\end{array}$ & 2078 & 56 & $5.2 \pm 0.6$ & 0.52 \\
\hline & $\begin{array}{c}\text { 4) } \mathrm{C}(2 \mathrm{LR}) \mathrm{EN} \\
\text { c bw }\end{array}$ & 2492 & 0 & 0 & 0 \\
\hline & Total & & & 49.5 & $x=0.51$ \\
\hline
\end{tabular}

${ }^{*}$ Yield of viable progeny was determined as the sum of imagoes that emerged in four crosses with various tester females.

\subsubsection{Conditional Mutations Are Damages in Genes (DNA)}

Conditional mutations have been generated by exposure to gamma-radiation, a widely used inducer of DNA damage; they have been recovered and maintained in culture as defects in certain chromosomes. The conditional mutations display lower stability in their manifestation as compared with the conventional drosophila mutations; however, this does not interfere with their handling as mutations. The frequency of conditional mutations in the $\mathrm{X}$ chromosome at a radiation dose of $30 \mathrm{~Gy}$ taking into account a decreased penetrance amounts to 4.95\% [10]. This rate corresponds to the frequency of sex-linked lethals in the X chromosome at the same irradiation dose. This high frequency suggests that the mutations displaying a conditional pattern may represent a broad class. The frequency of mutations belonging to this class may be even higher, since only the tubes with complete absence of daughters in the offspring were selected when recovering these mutations; however, there were some tubes containing single daughters, which could be also taken into account. "A high frequency of mutations and their non-allelism suggest that a large part of the genome is involved in the mutation process" [10].

Six of the 80 recovered conditional mutations additionally had a visible manifestation. In laboratory cultures, the conditional mutations were maintained as 
heterozygotes and acted as recessive lethals [6]. Presumably, the nucleotide sequences of conventional genes and the genes responsible for conditional mutations may partially overlap.

\subsubsection{Manifestation-Non-Manifestation of Conditional Mutations Depends on Spatial Factor}

A distinct association of the conditional mutations with DNA sequence makes them akin to classical mutations. The more drastic is their difference from the classical mutations in their manifestation. "Conditionality" is the dependence of mutation manifestation on the genetic specificity of the genome. Conditional pattern of their manifestation is not characteristic of the genes in the classical genetics. They are regarded as independent hereditary units.

Spatial factor is one of the "conditions" influencing the manifestation of conditional mutations. It has been discovered just by accident. The mutant males with a conditional mutation in the $\mathrm{X}$ chromosome gave no daughters in the cross with yellow females but gave daughters in the cross with the In(1)Muller-5, $y w^{2}$ females, also yellow in their phenotype but carrying the inversion in their $\mathrm{X}$ chromosome [20]. The data described in Section 1 of Results confirm this observation. The rearrangements localized to the chromosome opposite to the mutant one (Table 1 and Table 3), and to chromosomes in the genome of the partner (Table 2) influence the manifestation of conditional mutations. We may assume that the ability to influence the manifestation of conditional mutations is a general property of chromosomal rearrangements, which alter the order of chromosome regions in the nuclear space.

\subsubsection{A Decrease in the Fertility of Conditional Mutants and the Carriers of Chromosomal Rearrangements Suggests Impaired Gene Function in Germline Cells}

A decrease in the fertility of conditional mutants was noticed immediately on recovery of the first batch of such mutations [10]. This was recorded in a typical test assessing the ratio of viable progenies to the number of laid eggs (Table 4 and Table 5). With time, it had been understood that most of the performed tests for the conditionality of mutation manifestation were actually the qualitative tests for a decrease in fertility. The absence of a certain class in the offspring of a viable mutation carrier means that its fertility is decreased by at least the value corresponding to the size of the missing class. The conditional mutants are the individuals with drastically varying fertility depending on different but genetically precisely specified conditions.

A decrease in fertility should be recognized as the major and leading property of conditional mutations. The chromosome rearrangement, it appears, also possesses this property (Table 10). The hypothesis on existence of common stages in the functioning of conditional mutations and rearrangements, stated above (see Results, Section 1.5), is thus confirmed. A decrease in fertility in the case of a conditional mutation as well as in the case of a chromosomal rearrangement is combined with a normal phenotype of the mutation carrier. This means that the 
genome in the somatic tissues of a mutation carrier functions normally versus the germline cells, where it functions abnormally.

\subsubsection{A Decrease in Fertility Results from a Defect in the Genetic} Material in Gametes Rather That a Defect the Gametes Themselves The level of fertility of the conditional mutants changes owing to additional genetic changes within a mutant genome as well as the genome changes in its partner in cross. In particular, the fertility of a male carrying a conditional lethal depends on the genotype of the female to which it is crossed (Table 1 and Table 2 ) as well as the direction of cross (Table 6). The class of mutant sons is absent when they lack the $Y$ chromosome (Table 7 ), although the $X 0$ males are usually viable. If a "physical" defect of gametes as a whole entity (= their inability to form a zygote) were the cause of a decreased fertility, any "external" control of fertility would be impossible. Thus, it is the genetic program conveyed by the gamete that should be defective.

\subsubsection{The presence of Paternal Effect is an Evidence for the Genome Activity in Germline Cells as Well as a Proof That Conditional Mutations and Chromosomal Rearrangements Change the Genome Activity}

In the classical genetics, a phene is non-alternatively "coupled" with the gene. A mutant phenotype is manifested in a cell or an individual only in the presence of the corresponding mutant gene. The inseparability of gene and phene is the basis of the classical genetics. The paternal effects of conditional mutations and chromosomal rearrangements cancel this classical statement [29]. A mutant male with a conditional mutation in its $\mathrm{X}$ chromosome gives $50 \%$ sperm cells with the $\mathrm{X}$ chromosome (carrying mutation) and $50 \%$ with the $\mathrm{Y}$ chromosome (without mutation). However, it appears that the deleterious effect of conditional mutation expands not only to the daughter that got the mutant $\mathrm{X}$ chromosome in a regular way, but also to most of the sons that did not receive it (Table $4)$. The situation with morphoses is the same. In the cross of a yellow female with the mutant $(+)$ male carrying a conditional mutation in the $\mathrm{X}$ chromosome, the yellow sons did not get the mutant $\mathrm{X}$ chromosome but still part of them formed morphoses (Figure 2, except for Figure 2(f) and Figure 2(i)). In the cross of $C(1) D X, y w f$ females with the (+) males carrying a conditional mutation in the $\mathrm{X}$ chromosome, the $C(1) D X, y_{w}$ daughters did not get the mutant $\mathrm{X}$ chromosome but part of the daughters displayed morphoses (Figure 2(f), and Figure 2(i)). The paternal effect is repeated by the chromosomal rearrangements, decreasing the male fertility (Table 10 ). Note that both the progenies that received a rearrangement from their father and those that did not die as well (Table 10).

The natural question arises on what is the particular factor transferred to the progenies that did not received the mutation but nonetheless simulate the presence of mutation by either a lethal effect or morphoses. The only possible answer is that 1) the genes forming the basis of conditional mutations are active in the 
diploid germline cells, 2) they produce regulatory products that act on the overall diploid genome; and 3) this effect is transmitted to the progeny independently of whether it got the mutation itself with the gamete or not. The germline cells house a specialized group of regulatory genes the activity of which is similar to the gene activity in the soma during organogenesis.

\subsubsection{The Genome Activity in Germline Cells Extends to the Genes with a Regulatory Function (Ontogenes)}

The genome activity in germline cells may concern only the regulatory activity. As is known, morphogenesis there is absent. The facts of formed morphoses and modifications following a parental pattern suggest the presence of a regulatory activity in germline cells. The parental effect (especially, paternal effect) irrefutable suggests that the cause is an event that takes place before the meiotic reduction division. Correspondingly, we assume that a program for successive genome activity intended for implementation in the future offspring is formed in the mitotically dividing gonial cells. Because of uniqueness of the function and action site (germline cells), the genes responsible for development of this program got a special name, ontogenes, meaning the genes that control the course of ontogenesis. Still before uniting into a zygote, the gametes of different sexes already possess the main sections constituting the program for development of the $\mathrm{zy}$ gote. The general course of development is already determined. When the programs of the future development in gametes forming a zygote misfit, the zygotes die at the very first steps of their development.

\subsubsection{The Regulatory Products Generated by Ontogenes Are Short RNAs}

Two chemical compounds are formed on the basis of DNA template, RNA and protein. If a protein were the regulatory product formed on the ontogene, the ontogene in its properties would not differ from a conventional gene. However, this is not the case, as is evident from the specific features of conditional mutations mentioned in Introduction and Results. Consequently, only RNA remains to be the regulatory product in question. Indeed, this does not exclude that the genome contains the regulators of a protein nature.

The inference on the role of RNA as a regulator independently follows from the data on chromosomal rearrangements. Chromosomal rearrangements influence the manifestation of conditional mutations (Results, Section 1). This effect may be implemented by RNA, for example, short RNAs, but by no means a protein. For the rearrangements to influence the regulation, the regulator should not leave the nuclei. This condition can be met if short RNAs act as such a regulator. It is reasonable to consider that the chromosomal rearrangement changes the distance between the site where RNA is produced and the site where it binds the target. The distance between the opposite alleles of the ontogene also changes. In this case, the changes in spatial arrangement of chromosome regions should influence the regulation efficiency within the nucleus.

If a protein is the regulatory product in question, the chromosomal rearrangement cannot influence the regulation. For the molecule of a regulatory 
protein to be formed, the corresponding mRNA has to leave the nucleus for the cytoplasm to be translated on the ribosome and then return to the nucleus to bind to the target. The procedure of exiting the nucleus and coming back to it will annul the effect of intranuclear distances. It is known that the conventional genes, with proteins as their final product, do not depend in their manifestation on the presence of rearrangements in the genome. As is evident here, three conclusions made in this work favor RNA as the regulator in question, namely, 1) the regulator should be the product of a DNA region; 2) it is not a protein; and 3 ) its function is to be implemented within the nucleus.

Three large data sets favor the hypothesis on existence of the ontogenes that are active in germline cells. The first set of data, cytological, is related to the lampbrush chromosomes [30] [31] [32]; the second one, molecular, proves the existence of regulation via RNA interference [33] [34]; and, finally, the third set demonstrates changes in the level of methylation in gametes [35] [36].

\subsubsection{The Regulatory Product Generated by the Ontogene Is a Duplex}

The conditional mutations manifest in a variety of ways [6] but have an obligatory component in their manifestation, namely, a dominant lethality in a particular genotype (conditional dominant lethality). This suggests that the mutation in an ontogene that damages one of the two homologous sequences results in cessation of duplex formation and, consequently, cancels the regulatory function of the ontogene [37]. Thus, the genetic regulatory network composed of ontogenes in a diploid functionally manifests itself as a haploid ([4] p. 949). This particular structure of the system that controls ontogenesis imposes the prohibition on the changes in the species program of individual development. The action of a chromosomal rearrangement in a heterozygote is explainable by a spatial separation of homologous ontogenes. The already known mechanism underlying the effect of double-strand RNAi may be an indirect confirmation for the feasibility of hypothesized duplex nature of the ontogene product.

\subsubsection{Ontogenes Are Arranged into Multigene Families}

The existence of a dominant lethal mutation as a real laboratory culture is possible only if the mutant gene in the genome is at least repeated. Let us illustrate this as a figure (Figure 4). As is evident, the activity is transmitted from one gene (lower square) to another (upper square) via a regulatory chain, which includes a regulatory gene (circle). The regulatory function is duplicated. It can be implemented by either gene 1 or gene 2 (two genes is the minimal composition of a multigene family). One of the two genes (variants (a) or (b)) works in a particular organism. If working gene 1 (variant (a)) is mutated (variant (c)), the individual will die. If inactive gene 1 is mutated (variant (b)), the individual retains viability despite the presence of mutation (variant (d)). Thus, a damage of the active ontogene means emergence of a dominant lethal mutation and death of the zygote, while a damage of the inactive ontogene allows mutation to remain in a latent state in the status of a conditional mutation. 


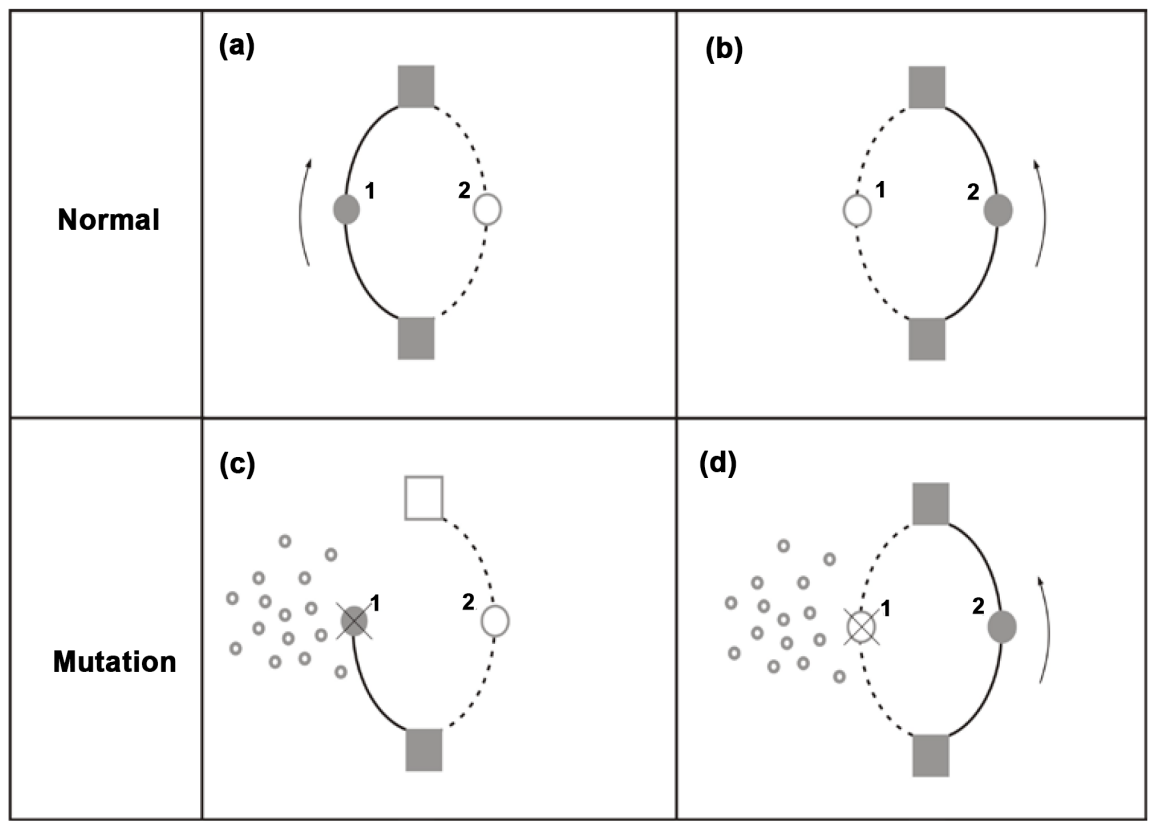

Figure 4. Scheme of the regulation of structural genes by regulatory genes (ontogenes). Two structural genes (upper and lower squares) are connected by a regulatory link. The lower structural gene activates the upper structural gene with the help of a regulatory gene (circle), which has two copies, 1 and 2. In the norm, copy 1 (variant (a)) is active in one genotype and copy 2 (variant), in the other. A regulatory event in the norm takes place independently of the number of active copy. In the presence of mutation in regulatory gene (variants (c) and (d)), the outcome depends on whether the mutation affected the active or inactive copy. Variant $\mathrm{c}$ shows mutation in active copy 1. A regulatory event does not take place (upper square is empty). Variant (d) shows mutation in inactive copy 2. The regulatory event takes place. Small circles denote hypothetical products formed on the mutant gene but lost their regulatory value.

Activation of one or another gene from the cluster depends on genotypic conditions, such as chromosomal rearrangement in the genome, sex of an individual, and specific features of the partner genome in cross [18]. The presence of the genes providing multiple duplication of the regulatory event provides for the constancy of a particular regulation type. Mutation will either destroy the overall organism together with the corresponding mutation or will allow the organism to live and utilize the corresponding old and validated program. In the proposed scheme, mutation of regulatory genes is not prohibited, prohibited are any changes in the functioning program of regulation. This is the particular condition that guarantees the constancy of living forms.

It is also evident from Figure 4 that the constancy of an organism within the species does not exclude the potential for changes. In the presence of a mutation, the old regulatory scheme can continue its function at the expense of collateral mechanisms. While they provide the regulation, a new regulatory program can establish in a hidden manner instead of the local functional chaos caused by the presence of mutation. On completion of a session of trials and errors, the lethal outcome caused by mutation can be replaced by a new viable state [20] [21] [22]. 


\subsection{General Pattern of the Genetic System Department That Controls the Course of Individual Development}

The fact that there exist the DNA regions (genes) determining the characters of the living organism forms the basis of the modern genetics. If a progeny inherits a particular DNA region from its parent, the corresponding character appears in this individual; if not, the character does not form. The procedure typical of recovery of the conventional mutations was used when dealing with conditional mutations: the conditional mutations were put in culture using a standard method; however, the corresponding DNA damages fundamentally differ from the classical genes in their manifestation.

The first distinction consists in the mode of manifestation of the mutant character. The presence of mutation in a parent is sufficient for mutation manifestation in the offspring (parental effect). A basic principle of the classical genetics-"where there is the gene, there is the phene"-is not met. The classical genetics also describes the inheritance that follows a parental pattern [38] [39]; however, the mutant characters inherited in a parental manner are rather few in collections of mutations. In our collection of conditional mutations, approaching a hundred of items, the parental type of inheritance of mutant character is the rule.

The second distinction refers to the form of parental effect. As a rule, the parental effect appears as a maternal effect [38]. As for the conditional mutations, the presence of both maternal and paternal types of the parental effect is characteristic of them [29]. Moreover, both types can be simultaneously present for the same conditional mutation. The maternal effect is determined by cytoplasmic inheritance [39], in particular, cytoplasmic inheritance of mRNA templates [40] [41] [42] [43] [44]. Here, we specially focus on the paternal type of parental effect in conditional mutations. Existence of the paternal form of parental effect means that the genetic system in its function (in addition to a standard transmission of DNA template) utilizes a certain mechanism of genetic information transmission not associated with the cytoplasm. As is known, the sperm cell cytoplasm is not included into the zygote. Moreover, the parental inheritance of morphoses concurrently in maternal and paternal forms suggests that the maternal inheritance in certain cases is not associated with the cytoplasm.

The third distinction is again related to the form in manifestation of conditional mutations. The mutations are referred to as "conditional" according to the method used for their detection. The mutation reveals itself under conditions of a certain genotype, being concealed under conditions of another genotype. However, this is true only for the property of dominant lethality. The fact that a mutant individual has survived by no means suggests that this individual is normal. The survived mutation carriers display a set of deviations from the norm. First and foremost, this concerns the fertility of mutants. The fertility is drastically decreased and most sensitive to the changes in the genome. Conditional mutations are entitled to be termed "the mutations with variable fertility". The conditionality of mutations in the majority of cases is just a qualitative test 
for a drastic decrease in fertility. This test detects a complete absence of a certain class in the offspring in a certain type of cross.

The death of zygotes in a cross, be it solitary or massive, accompanies any crosses in living nature. A genetic understanding of this phenomenon was absent for a long time despite its biological significance. However, conditional mutations allow for explanation of this phenomenon with the specific features in the function of regulatory genes (ontogenes).

The fourth distinction consists in a clear dependence in the manifestation of an ontogene on the spatial factor. As is known, a classical gene can be transferred to any distance from its original site without any noticeable loss in its function (manifestation). As it has emerged, the chromosomal rearrangements alone also decrease the fertility according to a parental type. The spatial factor, which is so necessary for the function of a living system from theoretical considerations, asserts itself in full force by the example of ontogenes.

Our results and their consideration suggest two important conclusions. First, along with the known genetic system providing the syntheses of proteins, fats, and carbohydrates intended for construction of a living organism and its function, there is the system providing genetic regulation of these syntheses. The latter system utilizes the same genetic template, DNA, and also works according to the principle of discreteness (ontogenes) but its final product is short RNAs rather than polypeptides. It is likely that this part of genome is larger than the former one and is able to solve the basic problems of designing the ontogenesis, providing for genetic similarity, and systems-based nature of all living organisms, etc., as was stated in the Introduction. This particular system with its specific features forms the background for the phenomenology of epigenetics. It is most likely that short RNAs are involved in the regulation; although the events that take place after formation of the RNA duplex are yet to be studied.

Second, the specific features in manifestation of the elements constituting this system (ontogenes) that have been discovered so far allow for understanding why this system for a long time escaped the focus of genetic research. Genetic mutations, the major tool and for a long time span the only tool of experimental genetics, are poorly suitable for the research into the regulatory part of the genome because of lethality of the mutations in regulatory genes. Genetics had to come a long way until circumventing this difficulty. A "present" of nature itself has emerged to be fundamentally important. It appeared that the regulatory system works in the way that "lethal mutations are not always lethal".

The known mutation Curly allows for an illustration of the ontogene and its differences from a classical gene. This mutation is linked with the inversion $\operatorname{In}(2 L R) C y$. As is evident from the obtained data, Curly combines the features of a classical gene mutation and an ontogene mutation. Its visible manifestation (curled wings) is the manifestation of a classical gene mutation. Every individual that receives $I n(2 L R) C y$ has the curly wings phenotype, independently of having received it from a father or a mother. The individuals that have not received $\operatorname{In}(2 L R) C y$ display no curly wings. However, Curly as an ontogene mutation 
changes fertility of its carrier, decreasing or increasing it (Table 2), changes the ratio of classes in the offspring (Table 2); and interacts with other conditional mutations. These manifestations of Curly are inherited in a parental manner, and the connection with inheritance of the $\operatorname{In}(2 L R) C y$ inversion is lost. A classical type of inheritance ("where there is gene, there is phene") demonstrates gene activity in the soma. A parental type of inheritance suggests the activity of a gene (in this case, ontogene) in germline cells.

The detection of ontogenes makes it possible to monitor the work of the regulatory system of the genome at the level of a whole organism, paying attention to fertility, development of morphoses and modifications, overall genome instability, and energy metabolism. The research into conditional mutations as a tool for studying ontogenes will give the insight into the pattern of damages in the main part of genomic DNA and expand our knowledge about the mutational variation of the organism as suggested by the classical genetics. The role of genetic processes in germline cells drastically increases. It cannot now be reduced to the meiotic reduction in ploidy and recombination. In each organism, the genetic program of individual development in part of its regulatory elements is checked and adjusted during the maturation of gametes.

\section{Acknowledgements}

The authors thank the Federal Research Center "Institution of Cytology and Genetics of Russian Academy of Sciences" for providing financial support for this work (budget project no. 0324-2018-0019) and A.A. Fedorov for his assistance with the artwork.

\section{References}

[1] Waddington, C.H. (1968) Towards a Theoretical Biology: Prolegomena. Edinburgh University Press, Edinburgh.

[2] Waddington, C.H. (1953) Epigenetics and Evolution. Symposia of the Society for Experimental Biology, 7, 186-199.

[3] Belousov, L.V. (2006) A Morphomecanical Aspect of Epigenesis. Genetica (Russ.), 42, 1165-1169.

[4] Chadov, B.F., Chadova, E.V., Kopyl, S.A., Artemova, E.V., Khotskina, E.A. and Fedorova, N.B. (2004) From Genetics of Intraspecific Differences to Genetics of Intraspecific Similarity. Russian Journal of Genetics, 40, 945-958. https://doi.org/10.1023/B:RUGE.0000041372.16880.02

[5] Chadov, B.F. (2015) About the Cause of Systemacy of the Universe and Parts of It. Eco-Potencial, № 2, 124-146. (In Russian)

[6] Chadov, B.F., Fedorova, N.B. and Chadova, E.V. (2015) Conditional Mutations in Drosophila Melanogaster: On the Occasion of the $150^{\text {th }}$ Anniversary of G. Mendel's Report in Brünn. Mutation Research/Reviews in Mutation Research, 765, 40-55. https://doi.org/10.1016/j.mrrev.2015.06.001

[7] Russo, V.E.A., Martienssen, R.A., Riggs, A.D. and Briggs, A.D., Eds. (1996) Epigenetic Mechanisms of Gene Regulation. Cold Spring Harbor Laboratory Press, New York. 
[8] Zakijan, S.M. (2012) Introduction. In: Zakijan, S.M., Vlasov, S.M. and Dement'eva, E.V., Eds., Epigenetics, SD RAN, Novosibirsk, 5-6. (In Russian)

[9] Chadov, B.F. (2015) Modern Metaphysics and the Cyclic Protomodel. Eco-Potential, №4, 53-73. (In Russian)

[10] Chadov, B.F., Chadova, E.V., Kopyl, S.A. and Fedorova, N.B. (2000) A New Class of Mutations in Drosophila melanogaster. Doklady Biological Sciences, 373, 423-426.

[11] Chadov, B.F. (2000) Mutations in the Regulatory Genes in Drosophila Melanogaster. International Conferences on Biodiversity and Dynamics of Ecosystems in North Eurasia, Novosibirsk, 21-26 August 2000, 16-18.

[12] Chadov, B.F. (2005) Features of Intraspecific Similarity and Peculiarities of Mendel's Approach to Study of Heredity. Philosophy of Science, 26, 94-114. (In Russian)

[13] Chadov, B.F., Chadova, E.V., Kopyl, S.A., Khotskina, E.A. and Fedorova, N.B. (2004) Genes Controlling Development: Morphoses, Phenocopies, Dimorphs and Other Visible Expressions of Mutant Genes. Russian Journal of Genetics, 40, 271-281. https://doi.org/10.1023/B:RUGE.0000021627.82588.41

[14] Chadov, B.F., Chadova and Fedorova, N.B. (2012) Epigenetic Phenomenology in Conditional Mutants of Drosophila melanogaster. Morphoses and Modifications. In: Zakijan, S.M., Vlasov, S.M. and Dement'eva, E.V., Eds., Epigenetics, SD RAN, Novosibirsk, 499-533. (In Russian)

[15] Chadov, B.F. (2005) Ontogenes in Drosophila melanogaster: Genetic Features and Role in Onto- and Phylogenesis. In: Modern Problems of Genetics, Radiobiology, Radioecology and Evolution, 195.

[16] Chadov, B.F. (2006) A New Stage in the Development of Genetics and Term Epigenetics. Russian Journal of Genetics, 42, 1053-1065.

https://doi.org/10.1134/S1022795406090110

[17] Chadov, B.F. (2007) Ontogenes in Drosophila melanogaster. Genetic Features and role in Onto- and Phylogeny. In: Korogodina, V.L., Chini, A. and Durante, M., Eds., Modern Problems of Genetics, Radiobiology, Radioecology and Evolution, JINR 1, Dubna, 80-91. (In Russian)

[18] Chadov, B.F., Fedorova, N.B., Chadova, E.V. and Khotskina, E.A. (2011) Conditional Mutations in Drosophila. Journal of Life Sciences (USA), 5, 224-240.

[19] Chadov, B.F., Chadova, E.V., Khotskina, E.A., Artemova, E.V. and Fedorova, N.B. (2004) The Main Effect of Chromosomal Rearrangement Is Changing the Action of Regulatory Genes. Russian Journal of Genetics, 40, 723-731. https://doi.org/10.1023/B:RUGE.0000036520.93159.a5

[20] Chadov, B.F. (2001) Mutations Capable of Inducing Speciation. In: Stegnij, V.N., Ed., Evolution Biology, Tomsk State University Press, 138-162. (In Russian) http://www.evolbiol.ru/

[21] Fedorova, N.B., Khotskina, E.A., Mitrenina, E.Ju. and Chadov, B.F. (2004) Chromosomal Rearrangements and Speciation: Explanation of the Relationship between Events. Vestnik of Tomsk University, № 10, 122-127. (In Russian)

[22] Fedorova, N.B., Khotskina, E.A., Mitrenina, E.Ju. and Chadov, B.F. (2004) Chromosomal Rearrangements and Speciation: Explanation of the Relationship between Events. In: Stegniy, V.N., Ed., Evolution Biology, Tomsk State University, Tomsk 3, 107-120. (In Russian) http://www.evolbiol.ru/large_files/chadov2005.pdf

[23] Fedorova, N.B., Chadova, E.V., Khotskina, E.A. and Chadov, B.F. (2009) Genetic Mutations Preparing the Speciation Process. In: Kunakh, V.A., Ed., Factors of $E_{X-}$ perimental Evolution of Organisms, Logos, Kiev, 24-29. (In Russian) 
[24] Chadov, B.F., Chadova, E.V. and Fedorova, N.B. (2017) A Novel Type of Gene Interaction in D. melanogaster. Mutation Research/Fundamental and Molecular Mechanisms of Mutagenesis, 795, 27-30. https://doi.org/10.1016/j.mrfmmm.2017.01.002

[25] Chadov, B.F., Chadova, E.V. and Fedorova, N.B. (2017) A Novel Type of Gene Interaction in D. melanogaster. Mutation Research, 795, 27-30. http://biomedical-advances.org/ep-20175-29/

[26] Fedorova, N.B., Chadova, E.V., Khotskina, E.A. and Chadov, B.F. (2010) Conditional Mutations: Obtainment by the Method of Morphoses. In: Kunakh, V.A., Ed., Topics in Experimental Evolution of Organisms, Logos, Kiev, 78-83. (In Russian)

[27] Chadov, B.F., Chadova, E.V. and Khotskina, E.A. (1986) Chromosome Conjugation in Drosophila. III. Similarity and Differences between Chromosome Pairing in Females and Males. Genetika (Rus), 22, 71-79.

[28] Ashburner, M. (1989) Drosophila. A Laboratory Handbook. Cold Spring Harbor Laboratory Press, New York.

[29] Chadov, B.F., Fedorova, N.B. and Chadova, E.V. (2013) Parental Effects of Conditional Mutations and Their Explanations. Russian Journal of Genetics, 49, 141-150. https://doi.org/10.1134/S1022795413020038

[30] Callan, H.G. (1986) Lampbrush Chromosomes. Springer-Verlag, Berlin, Heidelberg.

[31] Macgregor, H.C. and Varley, J. (1988) Working with Animal Chromosomes. 2nd Edition, John Wiley \& Sons, New York.

[32] Gaginskaya, E., Kulikova, T. and Krasikova, A. (2009) Avian Lampbrush Chromosomes: A Powerful Tool for Exploration of Genome Expression. Cytogenetic and Genome Research, 124, 251-267. https://doi.org/10.1159/000218130

[33] Fire, A., Xu, S., Montgomery, M.K., Kostas, S.A., Driver, S.E. and Mello, C.C. (1998) Potent and Specific Genetic Interference by Double-Stranded RNA in Caenorhabditis elegans. Nature, 391, 806-811. https://doi.org/10.1038/35888

[34] Matzke, M.A. and Birchler, J.A. (2005) RNAi-Mediated Pathways in the Nucleus. Nature Reviews Genetics, 6, 24-35. https://doi.org/10.1038/nrg1500

[35] Carlson, B.M. (2009) Human Embryology and Developmental Biology. 4th Edition, Mosby, Philadelphia.

[36] Baranov, V.S., Kuznetsova, T.V., Pendina A.A., Efimova, O.A., Fedorova I.D. and Trofimova, I.L. (2012) Epigenetic Mechanisms of Normal and Pathological Human Development. In: Zakijan, S.M., Vlasov, S.M. and Dement'eva, E.V., Eds., Epigenetics, SD RAN, Novosibirsk, 225-266. (In Russian)

[37] Chadov, B.F. (2002) The "Image" of the Regulatory Gene in Experiments with Drosophila. Russian Journal of Genetics, 38, 725-734. https://doi.org/10.1023/A:1016356418121

[38] Khün, A. (1927) Die Pigmentirung von Habrobracon juglandis Ashmed, ihre Prädetermination und ihre Vererbung durch Gene und Plasmon. Nachrichten von der Gesellschaft der Wissenschaften zu Göttingen, Math.-Phys. Klasse, 407.

[39] Khün, A. (1961) Grungri $\beta$ der Vererbungslehre. Quelle\&Meyer/Heidelberg.

[40] Sokolov, N.N. (1959) Interaction of the Nucleus and Cytoplasm in Remote Hybridization of Animals. Izd. AN SSSR, Moscow. (In Russian)

[41] Sager, R. (1972) Cytoplasmic Genes and Organelles. Elsevier, Amsterdam.

[42] Nusslein-Volhard, Ch. (1995) The Identification on Genes Controlling Development in Flies and Fishes. Nobel Lecture, 8 December 1995, 285-306. 
[43] Wieschaus, E. (1995) From Molecular Patterns to Morphogenesis; The Lessons from Drosophila. Nobel Lecture, 8 December 1995, 314-326.

[44] Korochkin, L.I. (2002) Biology of Individual Development (Genetical Aspect). MGU Press, Moscow. (In Russian) 